\title{
Paving the Path: Preparing for Microbicide Introduction-Report of a Qualitative Study in South Africa
}

\author{
Julie Becker \\ Rasha Dabash \\ C. Elizabeth McGrory \\ Diane Cooper \\ Jane Harries
}

See next page for additional authors

Follow this and additional works at: https://knowledgecommons.popcouncil.org/departments_sbsr-hiv

Part of the Family, Life Course, and Society Commons, Gender and Sexuality Commons, International Public Health Commons, and the Medicine and Health Commons

How does access to this work benefit you? Let us know!

\section{Recommended Citation}

Becker, Julie, Rasha Dabash, C. Elizabeth McGrory, Diane Cooper, Jane Harries, Margaret Hoffman, Jennifer Moodley, Phyllis Orner, and Hillary J. Bracken. 2004. "Paving the Path: Preparing for Microbicide Introduction-Report of a Qualitative Study in South Africa." New York: EngenderHealth, International Partnership for Microbicides, University of Cape Town, and Population Council. 


\section{Authors}

Julie Becker, Rasha Dabash, C. Elizabeth McGrory, Diane Cooper, Jane Harries, Margaret Hoffman, Jennifer Moodley, Phyllis Orner, and Hillary J. Bracken 


\section{PAVING THC PATH: Preparing for Microbicide Introduction Report of a Qualitative Study in South Africa}

\section{ENGENDERHEALTH}

improving Womeri's Health Worldwide

Population Council 


\title{
PAVING THE PATH: Preparing for Microbicide Introduction Report of a Qualitative Study in South Africa
}

\author{
EngenderHealth \\ Julie Becker \\ Rasha Dabash \\ International Partnership \\ for Microbicides \\ Elizabeth McGrory \\ University of Cape Town \\ Diane Copper \\ Jane Harries \\ Margaret Hoffman \\ Jennifer Moodley \\ Phyllis Orner \\ Population Council \\ Hillary Bracken
}


(C) 2004 EngenderHealth, International Partnership for Microbicides, University of Cape Town, and Population Council. All rights reserved.

440 Ninth Avenue

New York, NY 10001 U.S.A.

Telephone: $212-561-8000$

Fax: 212-561-8067

e-mail: info@engenderhealth.org

www.engenderhealth.org

This report was made possible through, in part, support provided by the Office of Population and Reproductive Health, U.S. Agency for International Development (USAID), under the terms of cooperative agreement HRN-A-00-98-00042-00. Additional research support was provided by the John D. Rockefeller Foundation. The opinions expressed herein are those of the publisher and do not necessarily reflect the views of the funders.

Cover design: Yury Dashevsky

Printed in the United States of America.

Printed on recycled paper. 


\section{TABLE OF CONTENTS}

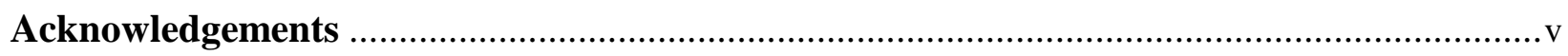

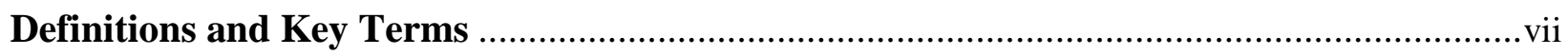

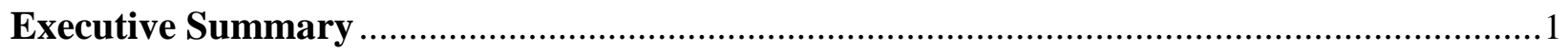

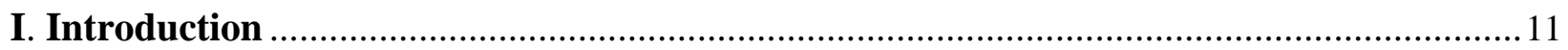

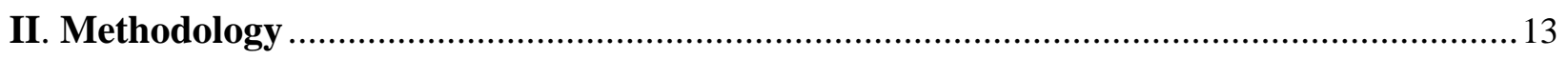

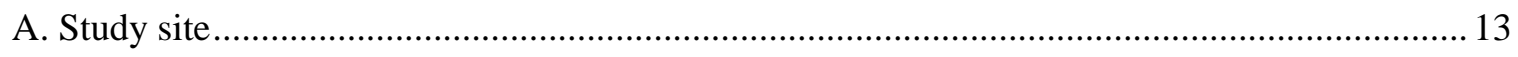

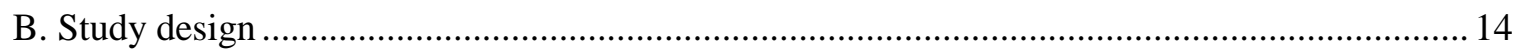

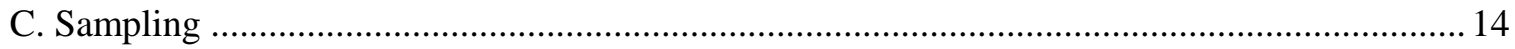

1. Community respondents ................................................................................ 14

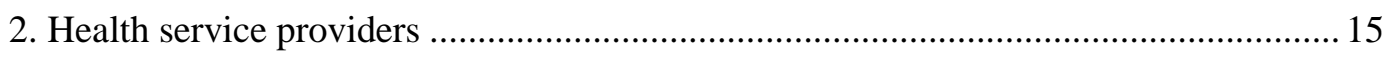

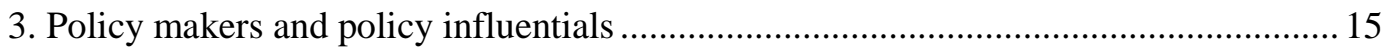

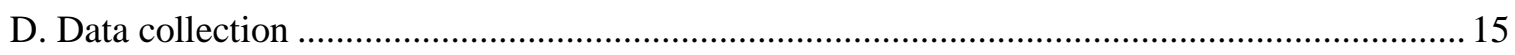

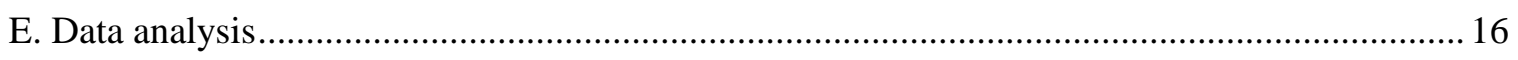

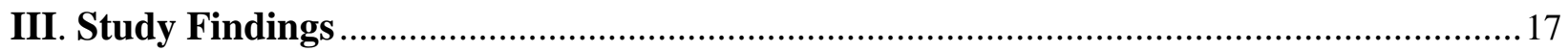

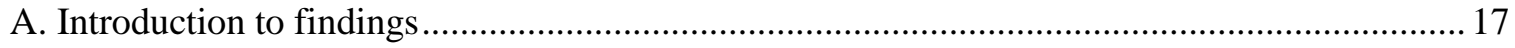

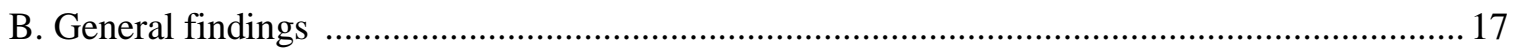

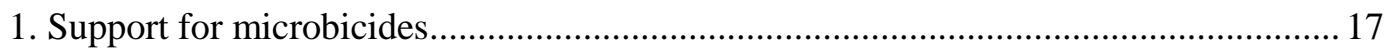

2. Condom substitution/migration ........................................................................ 19

3. Gender-power dynamics limiting women's ability to negotiate condom use................21

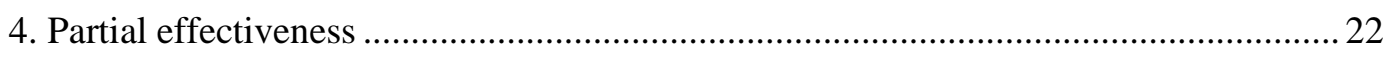

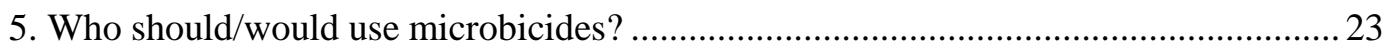

a. Range of potential users ........................................................................ 23

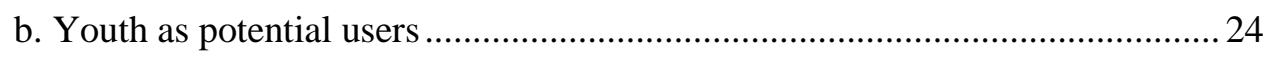

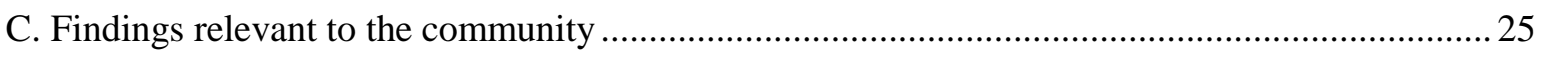

1. Rape, violence, coercion, and unplanned consensual sex ........................................2

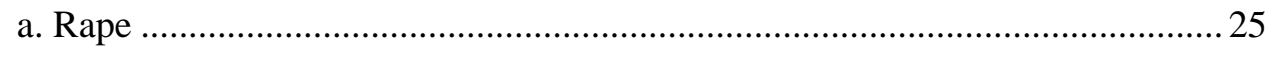

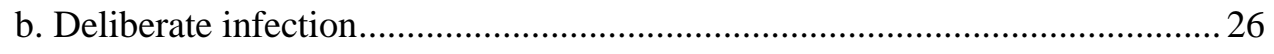

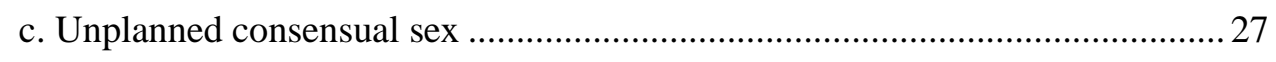

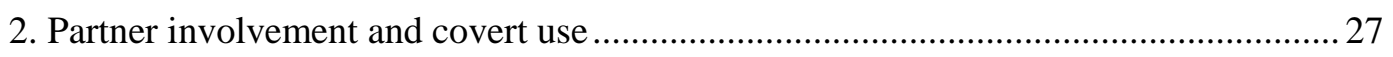

a. Partner communication and involvement.......................................................2 27

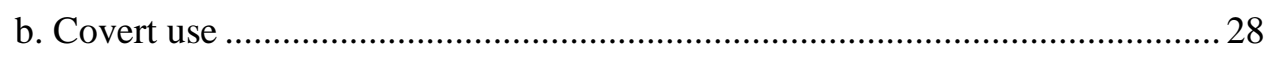

c. Limitations and repercussions of partner communication and covert use .......29 
3. Implications of local sexual and intravaginal practices ........................................... 30

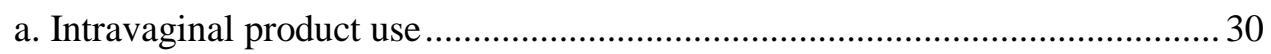

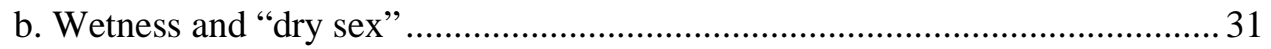

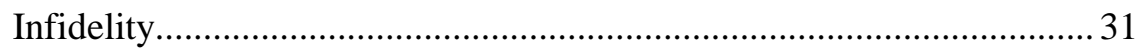

Sexual pleasure and "dry sex" ......................................................... 32

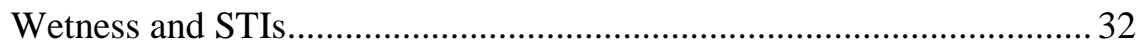

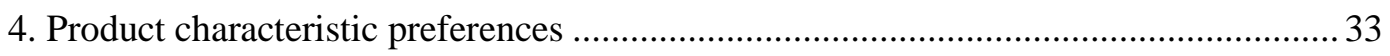

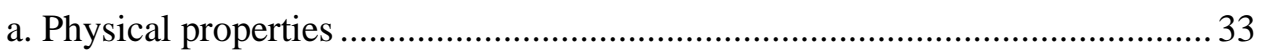

b. Applicator and mode of delivery ….............................................................. 34

c. Scope of protection: HIV, STIs, and pregnancy ........................................... 34

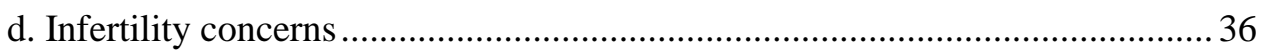

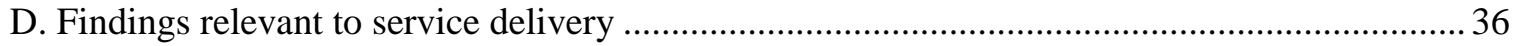

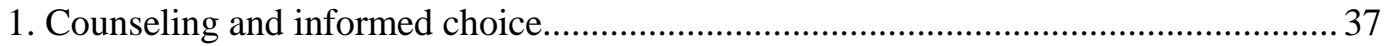

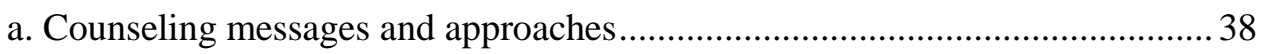

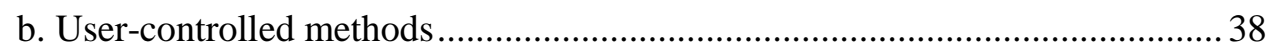

2. Integration into the hierarchy of prevention options and method mix .......................... 39

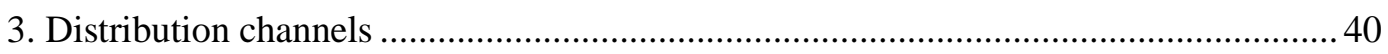

a. Potential avenues/venues for introduction and distribution ........................... 40

b. Assuring sustainability of supply ................................................................. 42

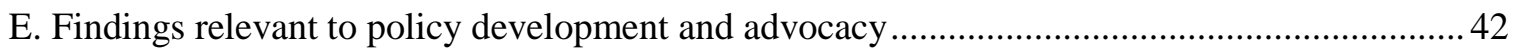

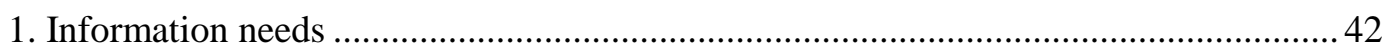

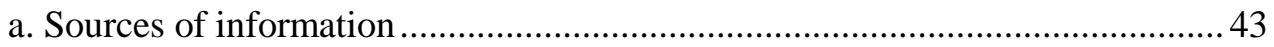

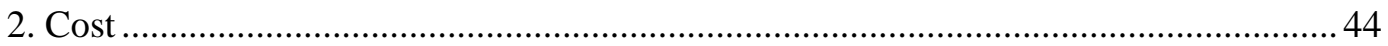

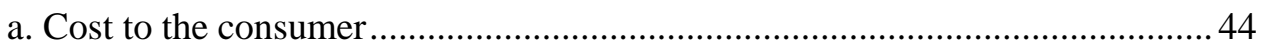

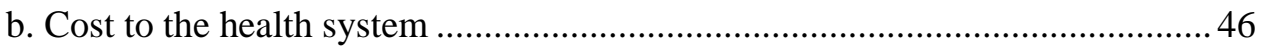

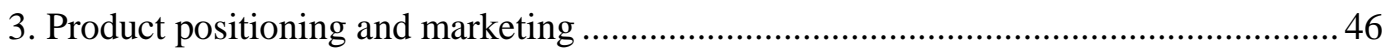

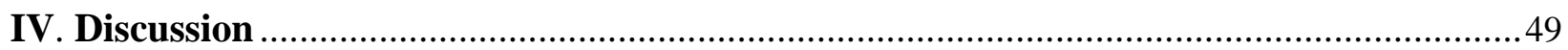

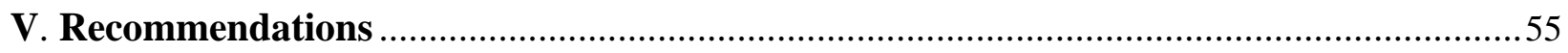

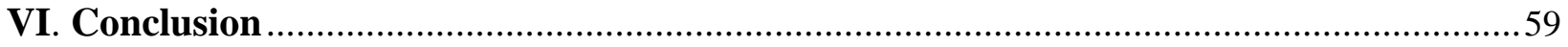

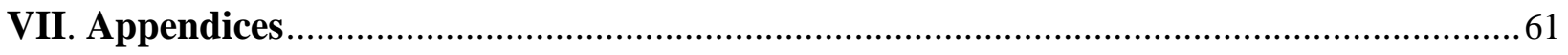

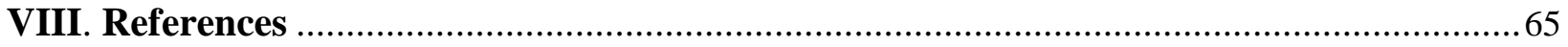




\section{ACKNOWLEDGEMENTS}

This research was implemented as a collaboration among EngenderHealth, the University of Cape TownWomen's Health Research Unit (UCT), The Population Council, and the International Partnership for Microbicides. EngenderHealth and its research partners wish to thank the primary funder of this research, USAID, for its support. We are also grateful to the Rockefeller Foundation for its supplementary financial contribution to this important work.

EngenderHealth would like to acknowledge the entire research team, who are also the primary collaborative authors of this report: Julie Becker and Rasha Dabash, EngenderHealth; Elizabeth McGrory, International Partnership for Microbicides; Diane Cooper, Jane Harries, Jennifer Moodley, and Phyllis Orner, Women's Health Research Unit, UCT; and Hillary Bracken, The Population Council.

We would like to acknowledge the following members of the community research team whose efforts were essential to acquiring the rich information presented in this report: Patricia Ngcelwane, Thandikhaya Mgoqi, Nontsasa Nako, Nomzamo Sishuba-Mbane, Notsuki Xapa. We would like to thank Nthuthu Manjezi, Program Manager, PPASA, Western Cape, and Clarissa Arendse, Branch Director, PPSA, Western Cape for assisting us in gaining access to the community where this research was carried out.

Our gratitude to the South Africa-based Local Advisory Group members-Marie Adamo, Alana De Kock, Vivienne Gongoto, Madoda Mabuto, Winnie Nonkonyana, Dominic Raphahlelo, and Brenda Smuts-for their critical guidance of this research.

Special thanks to the local and provincial health authorities for giving us permission to conduct serviceprovider interviews at the Langa Community Health Centre and the Vanguard Community Health Centre.

We would be remiss to not thank the respondents for their valuable time, candidness, and willingness to share their perspectives in informing research and introduction of future HIV prevention options for men and women in their communities and around the world.

For their advice and guidance throughout the project and development of this report, thanks to Margaret Hoffman of UCT and to Karen Beattie and Mark Barone of EngenderHealth. We also wish to acknowledge the contributions of Connie Lee, Marie Rose Charles, Georgia Holt, Inna Sacci, and Antigoni Koumpounis of EngenderHealth for their assistance, and Eleanor Marks and Nanette Rowland of UCT for their support. Appreciation also goes to Geeta Rao Gupta of ICRW for her assistance in the initial conceptualization of the project and to Sandra Waldman and Joanne Tzanis for their work in editing this report. 
Paving the Path: Preparing for Microbicide Introduction • vi • Qualitative Study Report 


\section{DEFINITIONS AND KEY TERMS}

Microbicides: A generic term for agents that can block, kill, or immobilize dangerous pathogens. These products, which are still under development, may offer the possibility for women (and men) to protect themselves from vaginal and rectal transmission of HIV and, potentially, other STIs. Microbicides will be used intravaginally and may be available in several forms (e.g., as a gel, suppository or film. It is also possible that they will be used rectally.

Partial Effectiveness: Refers to estimates of effectiveness of first-generation products ranging from 40 to 70 percent. It is anticipated that the effectiveness of initial microbicide products will be considerably lower than the effectiveness of condoms with perfect use (98\%).

Prevention Equation: Refers to the notion that a lower-efficacy product used consistently could have a greater impact on reducing infection at the individual and population level than a higher-efficacy product that is used less consistently. One of the premises for microbicide use has been that condoms, while highly effective when used "perfectly," are often used incorrectly or not at all because they can be difficult to use and are perceived as reducing sexual pleasure. Microbicides may be used more consistently if they are easier to use, perceived as interfering less with sexual pleasure, and their use can be initiated by women.

Condom Substitution/Migration: Refers to the concern that people who successfully use condoms might use microbicides instead, which could lower their overall level of protection.

Hierarchy of Methods: Refers to the offer of a range of methods by level of effectiveness, the risks and benefits offered by each method clearly identified. For example, if partially-effective microbicides were introduced into an HIV prevention program, a message about prevention technologies would be: "Condoms and microbicides used together offer the best protection against HIV. If you can't use both products, you should use male latex condoms every time you have sex. If you can't use male condoms, female condoms offer the next-best protection. If you can't use condoms, microbicides used alone could significantly reduce your risk of HIV infection."

Method Mix: Refers to the range of HIV/STI and pregnancy prevention methods or products available within a given program or service delivery setting.

Dual Protection: Refers to the prevention of both pregnancy and HIV/STIs through any of the following: use of a single product that prevents both (e.g., condoms); use of two methods (dual-method use, one for contraception and one for disease prevention); mutual monogamy with an uninfected partner using a contraceptive method; the avoidance of risky sex; or a range of other risk-reduction strategies. Although this term sometimes refers to protection against both HIV and other STIs, it is not used that way in this report.

Dual Methods: Refers to the use of two methods simultaneously (e.g. condoms and pills, or condoms and microbicides) to prevent HIV and pregnancy or to increase the effectiveness of an HIV prevention or pregnancy prevention method. 
Paving the Path: Preparing for Microbicide Introduction • viii • Qualitative Study Report 


\section{EXECUTIVE SUMMARY}

With recently accelerated support for the development of microbicides to prevent HIV transmission and the urgency of the global AIDS epidemic, it is important to begin to identify strategies for introducing a microbicide once it is proven safe and effective and is approved for use. This report presents results from a qualitative study that explored a range of issues likely to influence microbicide introduction — positively or negatively - at three levels: community, health service, and policy. The study identified critical issues to be addressed in building support for microbicides and facilitating smooth introduction.

Historically, technological innovations have had varying degrees of success in introduction; some have encountered significant obstacles that might have been avoided with more careful preparation. It is critically important to understand gender-related, social, economic, cultural, and structural contexts before any new innovation is introduced. This research aims to inform microbicide introduction strategies in an effort to avoid the delays and false starts that have hindered the introduction of new health technologies in the past.

The introduction of microbicides is likely to be complex for a number of contextual and product-related reasons. First, microbicides, especially the first generation of microbicidal products, are likely to be partially effective, with lower effectiveness than condoms in preventing HIV transmission. Second, microbicides will be "user-controlled" vaginal products that require acknowledgement and discussion of sexuality and sexual practices, issues that policy makers, providers, and users can find difficult. Finally, by potentially providing women with more power and control over their sexual lives, microbicides may challenge traditional gender norms. Given this range of complex issues, targeted social-science research into the beliefs and attitudes that are likely to affect understanding, acceptance, and use could greatly facilitate the introduction of this new technology. Such research can be used for informing policy, identifying necessary adjustments in the service delivery context, and guiding message development and product imaging for communities and users.

The study was conducted between September 2002 and September 2003 in Langa, a peri-urban site in the Western Cape Province of South Africa, and at national and provincial levels. Through in-depth interviews and focus group discussions, this study explored and identified issues that could facilitate or undermine access to and use of microbicides. The study included a range of respondents from the three levels of inquiry. Respondents included community members, health care providers and managers, provincial- and national-level government officials, and representatives from national and provincial nongovernmental organizations and health professional bodies that influence policy.

\section{KEY FINDINGS}

\section{The need for microbicides}

Respondents at all three levels expressed support for microbicide introduction. The severe effect of the AIDS epidemic on people's everyday lives and the urgent and desperate need for new approaches to help curtail the spread of HIV was the most powerful argument for microbicides to emerge from the data.

The respondents conveyed an understanding and acceptance of the reality of women's social vulnerability to HIV infection and the limits on women's ability to protect themselves, including the need for femaleinitiated prevention options due to widespread resistance to male condom use. Since microbicides are expected to be mostly female-initiated and controlled, participants felt that the products could provide an 
important option in giving women the ability to protect themselves with or without their partners' support.

The "prevention equation"- the idea that a lower-efficacy product, like microbicides, used consistently could provide overall protection at the individual and population level better than a higher-efficacy product, like condoms, used less consistently - generated little reaction when raised by the interviewers. It is not certain whether this was due to the concept being unclear, or because respondents did not need additional evidence beyond the devastating effects of the epidemic to make the case for microbicides.

\section{Partial effectiveness}

Respondents at all levels were concerned about the partial effectiveness of the first generation of microbicides, presented as ranging from 40-70\%. Despite apprehensions among a few providers and policy-makers about promoting a partially-effective method, most saw it as a trade-off to the high need and demand for such a product. They supported its introduction, pointing out that no method is "one hundred percent" effective, including condoms with typical use. Additionally, many providers and policy makers pointed out that the numerous barriers to condom use underscore the need for more acceptable prevention alternatives such as microbicides. The concept of a "hierarchy of methods" naturally emerged form the discussions. Some felt that microbicides should be positioned alongside male and female condoms either as a dual method or as stand-alone products to reduce risk where other, more effective prevention options are not feasible. The severity of the situation made women feel that it was preferable to take some action rather than to do nothing, even if microbicides were not 100 percent effective.

\section{Covert or overt use}

Women's lack of power in sexual relationships was cited as both a barrier and an incentive to microbicide use. Both women and men strongly recommended partner involvement and open communication about microbicide use, and many believed that such communication would be feasible. Other participants, however, felt that in the context of certain relationships, covert use would be a necessary alternative where there was a lack of trust between partners, where women lacked the power to negotiate the method's use, or where they feared repercussions, including violence, of raising microbicide use with partners. Community members, service providers, and policy makers alike questioned women's ability to negotiate microbicide use and said that even covert use might be difficult or could result in negative repercussions if discovered.

\section{Condom substitution}

Opinions varied about the potential impact of microbicides on condom use, specifically whether people who successfully use condoms would be likely to use microbicides instead. Some policy-level respondents worried that microbicide introduction could undermine condom use, particularly among adolescents. Some male — and female_-focus group participants indicated that they might, indeed, stop using condoms in favor of microbicides. In contrast, many respondents recognized that among many groups consistent condom use remains low, and felt that the introduction of microbicides would not decrease condom use. Instead, they felt that microbicides could potentially provide an important alternative for those who would not or could not use condoms.

\section{Rape and unplanned sex}

Respondents described several situations requiring a long-acting product that women could insert before leaving the house as a routine practice in case something unexpected or unplanned happened that would expose them to risk. Concerns about sexual violence were expressed strongly and discussed at length. In addition to their own fears, participants in community focus group discussions frequently raised the possibility of young children being raped. Respondents also felt microbicides would be useful when a 
woman had unplanned, but consensual, sex, or for protection in case a man attempted to infect them intentionally. People assumed that the product would be long-acting and convenient enough to be used daily. None of these possibilities was asked about directly or probed for; participants spontaneously raised them in many focus groups and interviews, indicating that this could be a potentially important role for microbicides.

\section{"Wetness" and lubrication}

Concerns emerged among respondents at all levels about "wetness," pertaining to the added moisture that a microbicide formulated as a gel or cream could provide during sexual intercourse. Wetness was discussed, for the most part, from three perspectives: a) a woman's vaginal wetness implying infidelity (i.e. she had been with another man); b) the preference of men for a "not wet" or "dry" vagina for increased sexual pleasure; or c) the association of wetness with sexually transmitted infections (STIs). Men were concerned that it would be difficult to distinguish whether a woman was wet due to the microbicide or because she had sex previously with another man, and women were anxious about being accused of infidelity. Many referred to men's preferences for the vagina to be dry or "not wet" (although this was not associated with the use of drying agents), indicating that wetness associated with microbicides could be perceived as negatively affecting sexual pleasure.

\section{Intravaginal product use}

Participants expressed wide-ranging and contradictory views about women's experience and comfort with the use of vaginal products. Women in focus groups said they were familiar and comfortable with using vaginal products and were already using tampons and "vaginal creams for thrush." Providers supported this view, although policy-level respondents gave mixed views, some expressing concern that women would be unfamiliar with or unwilling to use an intravaginal product.

\section{Product characteristics}

The aesthetic and physical characteristics of microbicides also were viewed as important intrinsic factors that could hinder or facilitate microbicide use. In terms of physical properties of the product itself, characteristics of concern included smell, messiness, stability at different temperatures without refrigeration, duration of effectiveness, and how well the product would adhere in relation to bodily functions (e.g., whether the microbicide would be washed away with urination). Respondents expressed discomfort with aspects of the sample applicator shown, and suggested alternative product forms.

Respondents at various levels of inquiry differed in their views on the preferred scope of protection against HIV, other STIs, and pregnancy. Women tended to prefer microbicides that would not prevent pregnancy, while more men favored products that also were contraceptives, although many presented contrasting views. Providers were keen on offering microbicides that could prevent a range of STIs in addition to HIV and were less interested in the product's contraceptive properties, while several policy makers felt that a microbicide with dual protection (contraceptive and STI prevention) could facilitate use and be a beneficial addition to family planning programs.

\section{Potential microbicide users}

Respondents thought that a wide range of people, including very young girls, youth, married and unmarried women, older women, and men, could potentially use microbicides. Health care providers were generally more comfortable categorizing appropriate microbicide user groups according to risk, particularly those with a history of STIs, HIV-positive individuals, sex workers, and those unable to negotiate condom use. Community participants and some providers suggested that youth should be the main users and beneficiaries of a possible future microbicide, because they were the most sexually active, did not use condoms, and were the most vulnerable to unplanned, unprotected, and coercive sex. 
However, some policy makers expressed reservations about targeting youth, citing in particular recent gains in condom use among this group.

\section{Need for information}

Policy makers, providers, and community participants all stated that they would need information about effectiveness, efficacy, safety, side effects, and contraindications before they would recommend microbicides to clients or support their introduction. Given that the first microbicides will not provide complete protection, both national and provincial level policy makers pointed out that clients must be fully aware of the implications of partial effectiveness. They emphasized a desire to have access to evidence from both animal and human clinical studies to determine whether microbicides were in fact safe and effective. Respondents' understanding of concepts such as safety, efficacy, and partial effectiveness were often erroneous; some policy makers highlighted the need to further examine the way in which information about these key concepts should be conveyed to potential users, policy makers, and providers, stressing the need for simple yet comprehensive information to facilitate informed choice.

\section{Distribution and marketing}

Participants across all three levels of inquiry also felt that microbicides should be distributed widely—not only in health clinics, such as family planning, well-baby, maternal health, and VCT centers, but also in places where women congregate and locations that are easily accessible in the community: chemists; supermarkets and shops where herbal medicines are obtained; local informal shops and bars; and community-based organizations. Despite a desire for widespread access, many respondents at all levels, concerned about safety and partial effectiveness, hesitated to endorse distribution of these products in venues where personal counseling is not available or quality control would be difficult to ensure. In community focus groups, men and women of all ages and socio-economic groups stressed the need for media campaigns and for community-based sources of information to be available at such places as churches, schools, libraries, and other community organizations.

\section{Sustainability of supply and cost}

Several policy-level respondents warned about the problems in creating demand for the product at the community level before supplies are sustainable. Citing some experience with the female condom, they underscored that a reliable and affordable supply needs to be in place before widespread marketing of microbicides begins. To address these concerns, and to allow users to become familiar with the products, some suggested a gradual introduction strategy. National and provincial policy makers, key policy informants, and providers all stressed that microbicides should be accessible to clients and provided at low cost or free. Some community and policy-level respondents supported the assertion of social marketers that products distributed in the public sector or free of charge are seen as inferior to other methods or products. Finally, a number of policy makers expressed concern about the cost to the health system, the lack of resources throughout all levels of the health system, and the difficult decisions that must be made among competing priorities.

\section{DISCUSSION}

A number of key results from this study - in areas such as product characteristics, condoms and condom substitution, partner involvement versus covert use, distribution strategies, and lubrication ("wetness")echo and expand upon findings of previous social science research and programmatic experience. However, several somewhat unexpected issues emerged quite strongly, such as the widespread understanding of women's vulnerability and their need for alternatives like microbicides, and the broad assumptions about microbicide use for protection in case of unplanned sex or rape. Several of these 
themes have direct implications for policy or further research related to product development and introduction.

\section{Support for microbicides}

Consistent with the growing recognition of the need for microbicides, respondents across the range of categories expressed strong support for product development and introduction. This interest derived from several related underlying issues that were described frankly and eloquently. First, participants exhibited widespread understanding and recognition of women's vulnerability to HIV infection. Many spoke openly - and spontaneously_about the underlying social, economic, and political factors that contribute to women's lack of control over sexual relations. Given the devastating impact of the HIV/AIDS epidemic in this setting, there was a real sense of desperation among community participants, providers, and policy makers for something that could help prevent HIV infection. Second, while respondents in all groups felt strongly that condoms must be promoted, there was widespread recognition of the limitations of condoms and their use. There was a strong sense that additional technologies and approaches are urgently needed, especially those that women can initiate, and a real frustration at the relatively long timeframe before an effective microbicide could potentially be made available.

Despite some concerns, the need and potential for microbicides resonated strongly with those interviewed for this study. This may be attributable largely to the impact of the HIV/AIDS epidemic and the vigorous public discourse on AIDS in South Africa; strategies for developing support for microbicides will clearly need to be tailored to other contexts. Even with the significant support among those interviewed for this study, participants expressed a number of concerns and uncertainties about microbicides, and an understandable need to know more about a specific product before they would approve, recommend, or use it. Therefore, while there seemed to be widespread general support for a product like a microbicide, a more specific case will need to be built based on the evidence from research and characteristics of a particular product.

\section{Implications of introducing a partially effective product}

As expected, the issue of partial effectiveness emerged as a major concern, particularly among providers and policy makers. Discussion underscored the challenges of accurately conveying complex messages about risk reduction and the options presented by a partially effective product. Initially, respondents across all three categories expressed some unease about the implications of introducing microbicides as "stand-alone" products, given that they will be less effective than condoms. Many were more comfortable with microbicides as a complement or addition to existing prevention options, and with including them as part of a hierarchy or method mix so that people would be able to choose from more options. A striking element of these interviews is how providers' and policy makers' concerns about partial effectiveness evolved from initial apprehension about practical and ethical implications to a more positive and affirmative view of the role microbicides could play in reducing individual risk and population-based incidence. This underscores some of the complexities of resistance to microbicides and suggests that some initial concerns and assumptions may be amenable to change.

\section{Condom substitution}

Policy and provider-level respondents expressed some concern about the possibility that introducing microbicides may lead people to switch from condoms to microbicides, undermining condom promotion and use. Some community members confirmed this possibility, indicating that they would welcome the availability of microbicides primarily because they would provide an alternative to condoms. Providers and policy makers reflexively positioned condoms as the "gold standard," although on further reflection most acknowledged the condom's limitations and that actual use among many groups is low. This suggests the importance of developing policy approaches and messages for introducing microbicides 
that accurately reflect actual condom use and the impact of condoms in HIV risk-reduction, rather than a theoretical ideal. In addition, while acknowledging that condoms are unpopular, participants rarely discussed perceptions or assumptions about the particular circumstances and types of relationships in which condoms or microbicides would be used.

Given growing understanding about how relationships and other circumstances influence condom use, it would be useful to explicitly explore these themes with respect to microbicides. Finally, concerns about condom substitution will likely shift along with any changes in condom use that may occur: if condom use increases before microbicides are introduced, condom substitution may become more of a concern. Given the long timeframe for microbicide development and introduction, this issue will need to be continually revisited in light of any changes in patterns of condom use.

\section{Rape and unplanned consensual sex}

One of the primary unexpected findings was the degree to which respondents across levels-especially community members-assumed that an important application for microbicides would be use by women to provide protection in case of rape. Rape is widespread in South Africa and has been extensively discussed and debated in the public arena, contributing to an acute awareness of the problem and a perception that it constitutes an immediate risk in women's daily lives. Women also discussed the utility of microbicides in the case of unplanned consensual sex. Both of these uses imply an assumption that women would be able to apply a microbicide as part of a daily routine. This would necessitate that a microbicide have a relatively long duration of action, and that it would be both affordable and convenient enough to be used daily. This has important implications for microbicide development and for how microbicides could be introduced or marketed.

\section{Wetness, lubrication, and intravaginal practices}

The issue of "wetness" resonated strongly with study participants as a serious concern. It has been an ongoing concern in the microbicide field that the lubricating properties of current gel formulations could compromise acceptability and widespread use of microbicides. Respondents across categories had different perceptions about how important added lubrication might be in hampering microbicide acceptability and use. Consistent with recent reviews of this issue, the extensive discussions and wideranging interpretations of lubrication in this study underscore the need to examine the actual meanings associated with wetness and lubrication in different settings, rather than relying on assumptions about practices and preferences. Similarly, the different perceptions of policy makers and community members with regard to women's comfort with intravaginal product use point to the importance of examining actual experience rather than assumptions. Beliefs and assertions by policy makers or providers that "women won't use them [microbicides]" because they are inserted vaginally could erroneously inhibit support for microbicides, even in settings where women regularly use vaginal products.

\section{Positioning and distribution strategies}

Findings from this study suggest that microbicides could be positioned for a wide range of potential users. While in other settings people often assume that "high risk groups," particularly sex workers, would be the most likely and appropriate users, respondents in this study suggested a much wider range, including children (in the case of rape) and "older" married women. It was widely assumed that younger, unmarried women, including youth, would be important users of microbicides; however, while this assumption was strongly supported by providers and community members, policy makers were less supportive of targeting youth due to concerns about potentially undermining recent gains in condom use and thereby increasing risk. There was strikingly little stigma associated with microbicides or the people who might use them, and a real sense that microbicides would be "mainstream" products. 
Suggested distribution strategies underscored the tension between making microbicides widely available in a range of clinical and non-clinical outlets and the challenges of conveying complex messages about risk reduction and partial effectiveness, which imply the need to control distribution to assure counseling and fully informed choice. Community members suggested a wide range of potential distribution points and strategies and cautioned against "medicalization" of the product. On the other hand, given that the first microbicides might be only partially effective, policy makers, providers, and community members hesitated to endorse widespread distribution without adequate counseling or information. There was some support for a compromise approach where products could be introduced first through a more formal clinical setting; then, once the public is familiar with the products' attributes and has some experience using them, more widespread availability could be phased in over time. In general, there was a strong sense that the best approach to positioning and marketing microbicides would be to build on strong, affirmative messages that would associate the product with a healthy, dynamic, positive, and modern lifestyle.

\section{RECOMMENDATIONS}

The recommendations presented below have been selected to highlight some of the less expected findings and areas requiring careful analysis in other geographical, social, and epidemiological contexts.

\section{Making the case for microbicides}

- "Make the case" for microbicides based on specific context: Further research in other geographical and epidemiological settings is needed to determine the best approach to "making the case" for microbicides. In this study, there appeared to be little need to convince people of the necessity for a product like microbicides. The broad recognition of the need for microbicides found in this study may not carry over to other settings where such issues are more hushed or stigmatized, where women's vulnerability is not as well recognized, where public discourse about AIDS and microbicides is less evident, and where cultural differences place greater restrictions on open discussion of sexual behaviors and practices.

- Communicate the rationale: Efforts to evaluate the acceptability of microbicides at the provider and policy levels will require dialogue and probing beyond immediate responses. Likewise, communicating the rationale behind microbicides will require more than simple messages. Despite broad support for microbicide introduction found in this study, initial responses were more mixed and muted. Opinions changed when people talked through the issues to arrive at their own conclusions, a finding that points to the value of qualitative research for in-depth exploration of issues. These findings also suggest the need for advocacy and introduction strategies to assure adequate dialogue.

- Understand how the "prevention equation" can be used: Further investigation will be needed to determine how the prevention equation is understood, and whether and how it could help to make the case for microbicides. It did not appear to be particularly important in convincing policy makers of the value of even partially effective microbicides in this context. However, this may differ in settings where the AIDS epidemic has not had as substantial an impact, and were microbicides may not be as readily accepted and supported.

- Use information on intravaginal practices to counter erroneous assumptions: Assertions that women will not use intravaginal products may not hold true, as shown in this study. Introduction 
and advocacy efforts may benefit from local data about actual use of intravaginal products to counter erroneous assertions that could undermine introduction efforts.

\section{Developing introduction strategies}

- Balance broad access with the need for counseling and informed choice: The possibility of using distribution channels outside of the health sector, or outside of clinical service delivery, should be further explored in preparing for introduction. It will be important to balance interest in assuring broad access with the need for careful counseling, particularly given partial effectiveness and the attendant hierarchical approach.

- Address provider information and training needs: To assure support from providers and providers' participation in introducing microbicides, strategies must pay careful attention to providers' information and training needs. Providers, who could be pivotal in influencing microbicide use, will need in-depth information on issues such as side effects and results of clinical studies, and training in order to feel comfortable recommending microbicides. They also will need support in formulating comprehensive yet simple counseling messages that allow clients to make informed choices. Although most providers in this study would likely support microbicides given adequate information, providers in other contexts may not be as receptive.

- Market for use with or without a partner's knowledge: Marketing and introduction strategies should take into account the need for both covert and overt use of microbicides. This study clearly demonstrated the desire by both women and men to communicate about microbicide use; however, respondents also recognized that many circumstances would require use without a partner's knowledge, and they noted the benefits of having a method that could not be detected.

- Consider youth as a potential target group for microbicides: Youth need to be seriously considered in clinical studies, introduction strategies, and further research as a potential user group for microbicides. Young people were spontaneously and consistently identified by various study participants as among the primary potential users of microbicides. The results point to the need to develop strategies that actively facilitate access and use by youth in South Africa while addressing some policy-makers' concerns about targeting youth. In different settings, even with similar needs, young people's access to sexual and reproductive health services may be more constrained, and receptivity to them as a user group may differ.

- Ensure a balance of supply and demand: Reliable supply and delivery systems must be in place before demand is created for a product. This is particularly important during the critical and sensitive introduction and scale-up stages. Although in this study only a few respondents reflected a broad distrust of "the system," introducing a product and failing to meet demand could potentially exacerbate such distrust, which could slow or halt introduction efforts.

- Enlist multisectoral support for introduction: Given the complicated nature of microbicides and concerns around partial effectiveness, enlisting the support of broad segments of society is likely to be critical. Several policy makers, policy influentials, and community key informants in this study stressed the importance of enlisting the support of individuals and organizations inside and outside of the health sector. The support of community groups, churches, labor unions, and others may be essential to "counter the fear of the unknown" that may come with the introduction of a new product. 
- Address diverse needs: It will be important to determine the possibilities for different microbicide products to meet varying needs and to continually reassess these as new methods with different characteristics become available. This research suggests interest in both free and low-cost products, the potential for use with or without a partner's knowledge, and appeal to different user groups, including married or unmarried people, youth, and sex workers. It also suggests the need for use under varying circumstances, such as daily routine use in case of unanticipated sex, and use in specific situations or with specific partners. Product characteristics such as contraceptive properties and formulations (gel, suppository, film, etc) could affect the range of potential market segments and needs.

\section{Further research}

- Use qualitative research to understand the complexities of perceptions about microbicides, and to allow new ideas to emerge: Further targeted, qualitative research designed to allow emergence of new ideas would be valuable to inform introduction strategies and to better understand the potential facilitating factors and barriers to microbicide use. In this research, effort was made to identify critical issues up-front based on previous research, review of the literature, and evolving discourse in the microbicide field. Nevertheless, several important issues that had not been anticipated emerged from the research. For example, the prevalent notion of routine microbicide use as a response to the threat of rape or sexual coercion, the notion that microbicides would be useful to put in "before you go out" in case of unplanned sex, and the importance of youth as a primary user group all emerged quite strongly from the data.

- Understand the meanings and implications of "wetness": Further research is needed to better understand how notions of vaginal "wetness" may impact the introduction of microbicides in this and other settings. "Wetness" emerged as a major concern, though respondents ascribed a variety of meanings to it ("wetness" signifies infidelity, reduces sexual pleasure, is symptomatic of an STI) and the research did not affirm a prevailing belief and concern among prevention and microbicide advocates that "dry sex" is idealized. Little is known about whether these same concerns would apply in other settings, and their implications for product development, marketing strategies, and education and counseling approaches.

- Investigate potential stigma associated with microbicides: The implications of stigma for microbicide introduction strategies in diverse settings is particularly important in considering distribution channels and marketing efforts. Although stigma against the product itself or against those who might need the product did not emerge in this research as a major issue, this may be quite different in other settings.

- Develop and test approaches to explaining partial effectiveness: Further research will be needed to determine approaches to explaining the meaning and implications of partial effectiveness. Partial effectiveness was clearly a major concern among all groups interviewed, and participants in this study varied widely in their understanding of the concept. Determining approaches to explaining concepts such as partial effectiveness for different audiences will be useful to ongoing research, advocacy, and ultimately, introduction efforts.

- Investigate the effectiveness and implications of microbicide use by HIV+ women: Given the growing population of HIV+ people in South Africa and elsewhere, further consideration needs to be given to the reproductive and other health needs of this group. This is particularly important in the context of more widespread availability of anti-retroviral treatment in South Africa and 
elsewhere and in the light of possible interactions between other contraceptive methods such as hormonal contraceptives for women, for example.

The challenges facing microbicide introduction are complex, as the findings of this study demonstrate, and respondent views have clearly been influenced by the sense of urgency and desperation in face of the devastating impact of the HIV/AIDS epidemic in South Africa. This study aimed to gain some understanding of the barriers and facilitating factors to microbicide introduction in the South African context. For some issues, we have a better understanding of how they are perceived, and the nature of concerns around them. Other issues have newly emerged from this research. Many will require further investigation and consideration in other epidemiological and socio-cultural settings. Some will prove to be more broadly applicable, and others are more specific to the local or national context. Successful and rapid introduction of microbicides, once they are approved, will clearly require further research and careful preparation. 


\section{INTRODUCTION}

With recently accelerated support for the development of microbicides to prevent HIV, and the urgency of the AIDS epidemic, it is important to identify strategies for introducing a microbicide once it is approved. This report presents results from a qualitative study designed to inform microbicide introduction strategies. The study focuses on a range of issues likely to influence microbicide introduction-positively or negatively-at three levels: community, health service delivery, and policy. It identifies critical issues to be addressed in building support for microbicides and developing strategies for their introduction. The results are intended to help define additional work needed related to policy, advocacy, and further research.

\section{Why explore introduction issues in advance?}

Historically, technological innovations have had varying degrees of success in introduction; some have encountered significant obstacles that may have been avoided with more careful preparation. Experience with introducing new health technologies has repeatedly demonstrated the importance of designing approaches to introduction that anticipate potential barriers and ensure a health service delivery and policy environment conducive to introduction. ${ }^{*}$ Such efforts include advocacy and public education to ensure accurate information about attributes and side effects, and to dispel myths or misconceptions. As such, it is critically important to understand the gender-related, social, economic, cultural, and structural contexts before innovations are introduced. This research aims to inform microbicide introduction strategies in an effort to avoid the delays and false starts that may slow the introduction of new health technologies and innovations. This study identifies issues that will require more in-depth analysis and action, and also suggests the degree of effort that will be required to prepare for introduction and the timing of additional research efforts and actions relative to the expected timeline for product availability.

The introduction of microbicides is likely to be complex for a number of contextual and product-related reasons. First, microbicides, especially the first generation of products, are likely to be partially effective. Yet, in situations where condoms are not used, microbicides may offer an important alternative for a woman to protect herself from HIV infection. It is also important that policy makers in particular understand that a method less effective than condoms, if used more consistently, could have an even greater impact on reducing HIV transmission for individuals and communities. Second, microbicides will be a "user-controlled" vaginal product that requires acknowledgement and discussion of sexuality and sexual practices, issues that policy makers, providers, and end-users can find difficult. Finally, by potentially providing women with more power and control over their sexual lives, microbicides may challenge traditional gender norms.

Given this range of complex issues, targeted social science research into the beliefs and attitudes that are likely to affect understanding, acceptance, access, and use could greatly facilitate the introduction of this new technology. Such research may be useful in informing policy by identifying necessary adjustments in the service delivery context, and guiding message development and product imaging for communities and potential users.

\footnotetext{
${ }^{*}$ A review of the literature on introduction of other health technologies and products with an analysis of the lessons learned as applied to microbicides is provided in a separate document.
} 
The study was a collaboration among researchers from EngenderHealth, The Population Council, the International Partnership for Microbicides (IPM), and the University of Cape Town Women's Health Research Unit (UCT/WHRU). A Local Advisory Group (LAG), which included stakeholders drawn from the community, public health practitioners, and policy makers, supported and informed the research design and implementation. 


\section{METHODOLOGY}

\section{A. STUDY SITE}

This study was conducted in South Africa, largely in the community of Langa, near Cape Town, and also included national- and provincial-level respondents. South Africa was selected for this study because it has among the world's highest rates of HIV infection, with more than 20 percent of the population infected. As in the rest of Africa, women are at high risk of HIV infection due to the confluence of physiological, socio-cultural, economic, and political factors. It is also the site for a number of clinical trials and acceptability studies of microbicides, and has a potentially sizable market for microbicides. Given the country's relatively extensive clinical and regulatory experience with microbicides, and the urgency of the epidemic, it is likely that South Africa will be one of the first countries to introduce a microbicide once safety and effectiveness are established.

Participants included community members and leaders, health care providers and managers, provincial and national-level government officials, and representatives from nongovernmental organizations and health professional bodies that influence policy. Interviews with policy makers and influentials were conducted at national and provincial (Western Cape) levels. Interviews with local policy makers, providers, and community participants and leaders were undertaken in Langa, one of South Africa's oldest townships ${ }^{*}$, situated on the outskirts of Cape Town.

Langa was selected as the study site with the assistance of the project's Local Advisory Group (LAG). Langa was established in the 1920s following passage of the Urban Areas Act, which forced Africans to live in demarcated areas based on race. Today, the township is a socio-economically heterogeneous community of almost 60,000; this is reflected in the diverse types of accommodation people live in, including an informal settlement area (Joe Slovo), rented accommodation (free-standing homes and flats), and home ownership, including formerly rented accommodation and suburban-type homes.

Both HIV statistics and services are limited in the study community of Langa; however, select data suggest a growing number of HIV infection cases and AIDS related deaths (Table 1).** There are no available antenatal HIV prevalence data for Langa; antenatal HIV prevalence in the Gugulethu/Nyanga district, the nearest comparable townships to Langa, was 16 percent in 2001.

Table 1. Trends in HIV Cases (1998-2002) and AIDS Deaths (1999-2002) Reported by Langa Community Health Center

\begin{tabular}{llllllr}
\hline & 1998 & 1999 & 2000 & 2001 & 2002 & TOTAL \\
\hline HIV cases & 56 & 73 & 208 & 411 & 535 & 1,283 \\
AIDS deaths & - & 79 & 96 & 120 & 130 & 425 \\
\hline
\end{tabular}

\footnotetext{
*In South Africa, the term "township" referred to residential areas earmarked for black South Africans. Under apartheid in particular, townships became synonymous with a policy of political, economic, and social control. ${ }^{* *}$ These figures are not necessarily a true reflection of the prevalence rates of HIV/AIDS in Langa. There are numerous reasons for underreporting. These cases are only those reported at Langa Community Health Centre. People might present elsewhere, go home to the rural areas to die, or not be tested at all for HIV/AIDS. Figures are underreported in South Africa and often AIDS deaths are not recorded as death due to AIDS, but to other opportunistic infections such as pneumonia.
} 


\section{B. STUDY DESIGN}

This qualitative study used focus group discussions and in-depth interviews to collect data from respondents. Research instruments were developed drawing on the project's conceptual framework based on current discourse in the microbicide field, as well as issues that emerged from a literature review on introduction of other health technologies and innovations. The instruments were designed to be openended and to include probes for potential additional issues that could emerge as important concerns among the various respondent groups.

To refine language and adapt questions to respondent needs, instruments and informed consent forms were pre-tested among service providers and community members. A district policy maker provided feedback on the policy maker interview guide. Following the pre-test, community instruments were translated to Xhosa and back-translated to English. Before conducting Focus Group Discussion (FGD) sessions, an additional nine pilot focus group discussions (six groups of women, three groups of men) were held by the community researchers in Xhosa in Khayelitsha, a nearby township. No data from these pre-tests are included in the research findings.

\section{SAMPLING}

Respondents (also referred to as participants) were identified using a combination of purposive and snowball sampling. Overall, 23 focus group discussions and 38 in-depth interviews were conducted with respondents at the policy, service delivery, and community levels (Table 2). A more descriptive breakdown of participant characteristics by level of inquiry is included in Appendix 1 of this report.

Table 2: Sampling by Respondent Level

\begin{tabular}{lcc}
\hline & Focus Groups & In-Depth Interviews \\
\hline Provincial and National Policy & 0 & 20 \\
Service Delivery & 1 & 7 \\
Community & 22 & 11 \\
TOTAL & 23 & 38 \\
\hline
\end{tabular}

\section{Community respondents}

Community focus group participants all resided in Langa and were stratified by age, gender, and socioeconomic status, using housing type as a proxy (i.e., type of residence: rented, homeowners, or informal settlement). In addition, four focus groups were held with community members of special interest (sex workers and taverners ${ }^{*}$ - see Appendix 1 for details). Respondents recruited for focus group discussions were approached individually by the Xhosa-speaking Community Liaison Officer (CLO) and briefly informed about the research project to determine their interest in participating. Those who fit the sampling criteria and were available and willing to participate were invited to attend the appropriate group discussion. Selection for the four focus groups of special interest differed in that the CLO recruited one or two participants who then brought other participants to the sessions.

Focus groups were stratified by age: younger women and men (18-25), older women (26-58), and older men (26-45). The mean age of men and women participating in the study was 31.2 and 30.5 years respectively.

\footnotetext{
* The term "taverners" refers to people who frequent informal bars that serve alcohol.
} 
Sixty-five percent of FGD participants owned or rented their homes and 95 percent were unemployed; there were no significant gender differences for both categories. Gender differences were seen in schooling: while 82 percent of the total had secondary education, more men (43 percent) than women (26.6 percent) had graduated from high school, but almost 16 percent of women as opposed to 5.4 percent of men had post-high school education (Appendix 2).

Community respondents who participated in in-depth interviews included traditional healers, teachers, outreach workers, and individuals from key community organizations, including NGOs located in Langa.

\section{Health service providers}

Public health nurses and doctors involved in reproductive health and HIV/AIDS services in Langa were contacted by phone or in person for interviews; private doctors were recommended by community members for interview. Individual in-depth interviews were conducted with three public health doctors, two private general practitioners, and two public health managers (also nurses) of local health facilities. In addition, one focus group discussion with five nurses was conducted.

Public health managers were women with nursing backgrounds, and all five public health nurses were women, consistent with the gendered nature of nursing in South Africa. They worked in the areas of maternal, child, sexual, and reproductive health. Given the limited health services in Langa, both the public health doctors and private general practitioners had considerable experience with communicable diseases, including HIV/AIDS and STI treatment and management.

\section{Policy makers and policy influentials}

The LAG and local researchers identified policy makers and policy-influentials (i.e. individuals who shape reproductive health and HIV/AIDS policy and programs). Policy makers interviewed included high-level managers and directors working in reproductive and sexual health, and HIV/AIDS directorates in the National Department of Health and the Western Cape provincial Department of Health. Respondents from the nongovernmental sector included local and international advocacy and service delivery organizations involved in HIV/AIDS, STIs, reproductive, and sexual health. Professional medical bodies and representatives from the media also were included.

\section{DATA COLLECTION}

Principal investigators, a senior researcher, and a project coordinator from UCT/WHRU were responsible for daily oversight of data collection and all field-based research activities. They also conducted policy maker and service provider interviews. Focus groups and some interviews with community members and leaders were conducted by a trained team of Xhosa-speaking community researchers.

On average, focus group discussions lasted approximately 1.5 hours and in-depth interviews lasted 1 hour. Informed consent was obtained from all participants prior to interviews and FGDs. For statistical purposes, confidential socio-demographic characteristics were collected on all FGD participants. Along with a description of

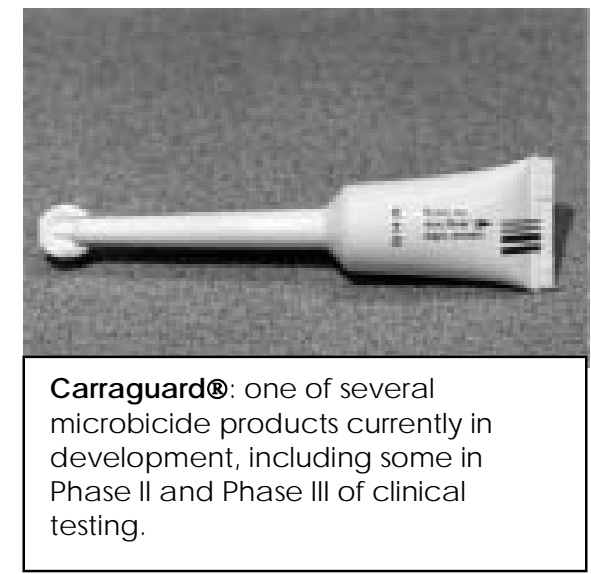


hypothetical microbicide products, an applicator similar to the one used in the Carraguard ${ }^{\circledR}$ clinical trials, pre-filled with K-Y Jelly, was shown to community participants as an example of a potential microbicide product.

Focus group participants received 30 Rand (approximately US\$4) to cover transportation costs incurred to attend the sessions, and refreshments were also provided during sessions. Interview respondents received no compensation. All interviews and sessions were tape-recorded and the tapes were later transcribed verbatim in English. Community in-depth interviews and focus groups conducted in Xhosa were simultaneously translated and transcribed into English by a professional translation/transcription service.

\section{E. DATA ANALYSIS}

Data analysis was performed using a modified grounded theory approach-a process that allows researchers to "discover" categories, themes, and patterns that emerge from the data ${ }^{12}$. To facilitate data management and sorting, Atlas.ti, a software package developed for qualitative data, was used. Initial categories for analysis were drawn from the interview guides, and additional themes and patterns emerged after reviewing the data within and across respondent groups. In May 2003, the entire research team met in Cape Town to review all data, identify major trends and cross-cutting themes, and prioritize issues for further exploration. At this time, a strategy and timeline was developed for the collaborative writing of this report. 


\section{STUDY FINDINGS}

\section{A. INTRODUCTION TO FINDINGS}

Research findings are presented according to both topic and the levels of inquiry to which they have particular relevance. This section begins by presenting findings on general issues that relate to all three levels of inquiry, including the need for microbicides, partial effectiveness, and information needed to facilitate recommending or using microbicides. It explores and contrasts perspectives of all respondent groups to provide readers with a broad view of how the range of study respondents perceived the same issue. For example, did community, providers, and policy makers understand the need for microbicides in the same way, or did their perspectives differ based on their background and exposure to the issues?

The subsequent sections correspond to the study's three levels of inquiry: community, service delivery, and policy. Each section includes topics that are of particular relevance to that level of inquiry, and presents the perspectives of all respondent categories together. For example, the issue of covert microbicide use is discussed under findings relevant to the community and includes providers' and policy makers' perspectives as well as those from the community level in order to compare and contrast views. In some instances, only one or two respondent levels are included, indicating that there was little data from the other group(s). This section on study findings is followed by discussion of the results and recommendations.

\section{B. GENERAL FINDINGS}

This section presents findings on topics that are relevant across all three levels of inquiry-community, service delivery, and policy - and draws on responses from all respondent categories. Within these general areas, respondents voiced a broad range of perceptions and opinions. Their reasons for supporting microbicides tended to focus on the desperate need for more prevention options in light of the HIV/AIDS epidemic, the recognition that many individuals do not use condoms, and the limited power of women to negotiate a male-dependent method. Partial effectiveness was the major concern expressed by most respondents. In addition, a wide range of individual concerns and questions about microbicides emerged from the data. The following sections present the most common reasons for microbicide support, as well as a range of concerns related to microbicide introduction.

\section{Support for microbicides}

Although respondents across all three levels of inquiry understood particular aspects of microbicides differently (for example, how they could be used, who should use them, how they would work, and so on), the vast majority clearly saw the need for microbicides and was supportive of microbicide introduction.

While it was expected that a case would need to be made for microbicide introduction, results suggest that there is already a strong case for microbicides in South Africa. Respondents at all levels recognized and often spontaneously and eloquently articulated the limitations of existing prevention options, as well as women's particular vulnerability to HIV infection, including the social and economic constraints that condition their risk of infection. Respondents, particularly community members and providers, conveyed a sense of desperation and urgency for additional prevention options in light of the devastating impact of the HIV/AIDS pandemic in South Africa. Community respondents evinced a marked sense of desperation 
and urgency in the face of the epidemic, while many service providers voiced a feeling of despondency. The feeling of powerlessness and confusion was expressed by many, including one male focus group participant who noted, "Everyone is at a loss about this AIDS."

Overwhelmed by a tragedy unfolding on their doorsteps, almost all community respondents supported introducing even a partially effective microbicide product due to the severity of the situation in South Africa and the need to take action. Without probing, respondents often raised the subject of burials of people who have died from AIDS as a daily feature in their lives. "...We are dying like fleas," was how one community woman articulated the enormous impact, while a male community member explained:

"No one will not want to use this method because we are getting finished out here, we bury everyday... this medicine will help us not to die the way we do."

-Man (26-45 years), owner

Similarly, one community leader suggested that sexually active people of all ages would be interested in using microbicides because "they can now see that our nation is dying."

"I'm sure everybody will want [this method], because everybody wants to know how they can protect themselves. It's terrible out there, people are dying, there's a child who has just died from HIV at the place where I come from. They are getting finished and they really get sick when it gets to this stage. AIDS is a difficult issue."

-Community leader

Dying or "getting finished" were predominant signifiers in the discourse on desperation and urgency. Community respondents repeatedly spoke in these terms about microbicide use, which many saw as a choice between life and death. One male focus group participant described the method as "interesting for those who did not want to die."

Many health service providers were despondent in the face of the epidemic and their limited ability to help prevent or treat the disease. "I would do anything. I would do anything to prevent the spread of infection. Whatever helps," one public health doctor said.

Providers related their concerns and frustrations to their experiences as health care providers. They conveyed a sense of being overwhelmed and feel the need for more alternatives as they care for infected and dying patients. Providers commonly spoke about the need for more options in the face of epidemic levels of STI infections.

"Well, if it's [microbicides] something that is going to lessen the spread, I'm thinking that is going to be very important...because we as carers, we would love to see such things happening, because at this moment in time really our hands are full in the HIV, STIs areas."

—Public health manager

Like community members, some providers also spoke of their sense of desperation as a result of being confronted with a growing HIV epidemic.

"I would accept any help - I would be prepared to try anything. I'm so desperate I just want to try anything."

[Interviewer: "Really? Is it that bad?"]

"It is. It is. It is bad."

-Private doctor

While this sense of desperation was common among community respondents, providers, and some policy makers, other policy makers voiced a more cautionary sense of need. With some distance from the death and devastation, many policy makers recognized the need for more prevention options, but felt that all the 
benefits and limitations of a potential microbicide product should be weighed before approval or support for the product could be offered.

\section{Condom substitution/migration}

The fear of condom substitution (condom users switching to microbicides, sometimes referred to as "condom migration") has been cited as a potential barrier to the widespread endorsement of microbicides as a potential method of HIV prevention. ${ }^{9}$ Findings suggest that while this was an issue of major concern among participants, participants did not generally feel that it was a reason to not introduce the method. In many cases, concerns related to condom substitution were tempered by a broad recognition of the difficulties and limitations of condom use.

Problems associated with the use of male condoms were raised by most community members, including some community leaders. Opinions varied about the likely impact of microbicides on condom use, specifically whether people would abandon condoms in favor of microbicides. These responses often reflected people's personal experiences. Similarly, policy influentials and providers expressed varying levels of concern about the possibility of condom substitution with the introduction of microbicides. Several national and provincial key policy influentials and providers felt that condom substitution was a real "worry" or "quite a big challenge."

Those who expressed deep concerns often looked to the possible detrimental impact on young peoples' use of condoms which, they assessed, was on the rise. Nonetheless, policy makers, policy influentials, and providers recognized that condom use was neither universal nor consistent even among "condom users." While several policy makers felt that condom use was increasing, others recognized the difficulties of assessing if, how, and when men and women were actually using condoms.

When asked how microbicides would fit into existing HIV/AIDS counseling programs, many policy makers and providers were torn between a desire to provide clients with choice, and a need for strong public health messages that emphasize condom use. One respondent was particularly concerned about the consequences of clients' choices.

"That's my worry from a public health point of view, it would be, 'Well, now you're potentially putting them more at risk than they were before by giving them this alternative.'... How to stop that? Not easy. ... You give people choices but that's why I'm a little bit worried about the consequences of that."

-Provincial policy influential

A few providers, wary of the idea of recommending that microbicides be used together with condoms, feared that, if asked to use two methods, clients might choose microbicides over condoms. Some feared that this could undermine already low condom use and previous work around condom promotion.

"Trying to get them to use a condom is very difficult and now we are asking them to use two things instead of one thing. That would be a problem for me as far as education goes. And then again, they might just decide that I can use only one of two and then might opt for the microbicides rather than the condom."

-Public health physician

Some male focus group respondents indicated that they may indeed stop using condoms, underscoring the concern of policy makers and providers. They felt that with the introduction of the microbicide they would no longer need to use a condom and that their partners would appreciate this, as women do not like 
condoms either. Some women in focus groups expressed similar sentiments regarding their discontinuing condom use.

"What will give interest in this cream is the fact that we won't have to use a condom anymore, which is what men want, so when applying the cream underneath, men will be happy. There will be no problems like there were previously with a condom. It will now be the flesh-on-flesh that they insist."

-Woman (26-45 years), informal settlement

In contrast, a national policy maker agreed that there was "more confidence in condoms than ever before" but felt that the introduction of microbicides would not decrease condom use. A provincial policy leader noted that the introduction of the female condom had not brought about a significant decrease in the use of condoms and microbicides would likely prove no different. The participant felt the "more options the better;" and that women should be able to choose their method of protection based on their own situation.

Community leaders raised some concerns about condom migration but felt overall that the microbicide could potentially provide an important alternative to condoms, which are unpopular. One respondent was not particularly concerned about condom migration. She felt that in the context of the AIDS epidemic and low condom use, the microbicide would provide a positive alternative. She later suggested using a microbicide in conjunction with a condom.

“... But I think also the idea of [microbicides] must not be separated from a condom. I strongly believe that the one must not be an alternative of the other. I think like contraception and condoms, they must come together. I think this microbicide and a condom, I really think that they should be seen as being partners, and that when you use them both, instead of being $99.9 \%$ with condoms or $70 \%$ with the microbicide then we'll be having $150 \%$, with both of them."

-Community key informant

Both policy makers and providers felt that through selectively offering microbicides to certain groups of clients, condom substitution could be minimized. Several providers stated that they were not overly concerned about condom substitution because of microbicide introduction. Asked if she would be concerned if clients stopped using condoms, one provider said,

"I don't think so, it's just choice...I think, for those that don't like [condoms] anyway they were not going to use it. For those that feel that they're scared of HIV, they'll use it."

-Nurse

Men in focus groups were not uniform in their attitudes towards condoms, recognizing that "people are not all the same." Issues around condom substitution were not clear-cut and male community members grappled with the implications of not using a condom versus using a method that was not 100 percent effective.

Finally, findings confirmed what has been widely reported elsewhere about people's dislike of condoms, difficulties using condoms, and inconsistency of use. A provincial policy maker remarked, "We've had 20 years of AIDS but ... I think we no longer fully appreciate the complexity of condom use." Women in focus groups frequently mentioned men's reluctance and/or refusal to use condoms. The microbicide would thus not only provide them with a female-initiated alternative but also one that would also be "attractive" to men, largely because "they are always reluctant when things are made for them" and because women and not men will have to use it. In addition, because microbicides may be the only option for some women, failure to provide microbicides could place policy makers in a "difficult ethical position." Since many men refuse to wear a condom because it inhibits sensation, women felt 
microbicides would be more attractive vis-à-vis condoms. "They will be able to eat the sweet without the wrap."

\section{Gender-power dynamics limiting women's ability to negotiate condom use}

Policy makers, providers, and women all acknowledged the difficulties women face in negotiating condom use, while several male community members did not agree that women had limited power to get their partners to use condoms. Both provincial and national level policy makers recognized that a woman's attempt to convince her partner to use a condom could result in domestic violence and accusations of infidelity. Policy makers, in particular, frequently referred to women's "lack of power" in sexual relationships as a compelling reason for providing female-controlled alternatives to HIV prevention.

Community women often noted that it was generally difficult, although not impossible, to negotiate condom use with male partners. One woman stated, "Men don't want women to have a say, especially regarding sex; even with the condom, they complain." Many women said that condom use could be associated with complaints, mistrust, fights, and even violence or abandonment. A nurse participating in one focus group said, "Women are the ones that should always negotiate ... and it's difficult for them." A microbicide's potential to offer an alternative when men refuse to use condoms was a recurring theme expressed by women in discussing their desire for a prevention method that they themselves could initiate. "When one wants the partner to wear a condom, they refuse and accuse one of sleeping around, but with this, one is in control. One can simply put it on and be safe."

Several participants suggested that covert use might be particularly desirable for young girls due to their lack of power in sexual relations, indicating that they could use microbicides "and nobody would be the wiser." If men knew about microbicides, they may feel that it could undermine their power in sexual relations.

“...at least one knows one is protected because some men beat you up for using a condom and want to find out why...At least there would be no problems, you would know that you are safe, even though you would not tell a man, you would personally know that you are safe."

-Female taverner

Providers and policy makers alike considered microbicides as a potentially empowering option to women who had few or no realistic prevention options. An informant from the media spoke about the limitations of other STI and HIV prevention methods and the inability of many South African women "to negotiate safe sex with their partners," concluding that the microbicide would provide an empowering alternative.

"It's [microbicide] an empowering tool really. Women will be able to actually decide what happens in their sex lives. They will be able to control that [by saying] that 'This is where the buck stops. I'm not going to get HIV because nobody should get it." ",

-National policy influential

Some men from the community said they would support a female-initiated method. Despite this, many women were skeptical as to the likelihood that men would actually support the use of microbicides in their own sexual relationships. Others believed that men would see this as a "good thing," since they did not want to wear condoms.

"Yes they will be interested...Because most males do not want us to use a condom, and therefore this microbicide will be most helpful towards us women."

—Woman (26-45 years), informal settlement 
While a few men in one focus group discussion spoke about how the microbicide would enable women to have some "power and control" over their sexual practices, most male community members saw the situation differently. Although several men spoke of their (or their partners') dislike for condoms, they suggested that they generally "give in" and go along with whatever their partners may suggest.

"Men are also easy to convince, so if this will be admitted by women and moreover get used by them, we males will vote for it, because if a woman says, I'm using such and such a method and you disagree, you will end up giving in."

-Man (26-45 years), owner

Several women in community focus groups suggested that even if men were to support microbicide use, it be motivated by a desire to allow them to continue engaging in risky sex, not to support women. Women in focus group discussions said that men would exploit microbicide use by seeing it as an opportunity to "sleep around as much as they like," and that an added attraction for men would be that "this would make it easier for them to sleep around and still not get infections."

A few providers and policy makers also felt that the microbicides may give men reason to refuse condom use, and that their existence could mean that women wouldn't have as much leverage to insist on condom use. Others, including one public health doctor, emphasized that a single product could not be expected to "empower women," stressing that empowerment was in fact a much larger process requiring the change of inequitable socio-cultural expectations and gender norms.

\section{Partial effectiveness}

The issue of partial effectiveness concerned many providers and policy makers. However, the range of individual concerns expressed about introducing a partially effective product, and the challenge this would present for information provision and distribution strategies, were generally tempered by a wide recognition that even a partially effective product would provide an important additional option for women and men and could increase overall protection.

"It's important for people to understand that condoms on their own are not going to be $100 \%$ safe, but it's also important from the point of view that there are people advocating that we must not be introducing technologies like condoms or like microbicides because there is a risk associated with them. Yes, there's still a risk of transmission associated with them, but we need to understand that the type of shifts in overall risk profile that are needed in South Africa will be achieved by the cumulative effect of a number of strategies, getting people to wait 'til they're older to have sex, sticking to one partner, persistent condom use, and so the microbicide is yet another additional piece of armor, if you like, in the overall fight against HIV/AIDS."

-National policy influential

A few policy makers and providers suggested that partial effectiveness of a first-generation microbicide was a trade-off to the high need and demand for such a product. One policy maker saw first-generation microbicides as prototypes for additional prevention technologies in the future, and that demonstrated demand would promote the development of more prevention options.

When first told that first-generation products might be between 40 to 70 percent effective, some community respondents and a few providers were confused about what this meant. Some struggled with understanding and using the terminology, often resorting to using effectiveness, efficacy, and safety (from infection) interchangeably. A few providers also expressed concern about how such complex concepts could be explained to clients. However, most providers did recognize that no method was "one hundred 
percent" effective, including condoms, and that while "some people are comfortable with condoms, [other] people are not."

Nonetheless, a few providers had concerns about offering microbicides as a stand-alone product, with one provider suggesting that offering microbicides when there are more effective methods could be considered "unethical medically." Some providers explained that they would be uncomfortable offering a partially effective product, thereby exposing clients to a partial risk of infection. One private physician insisted that microbicides should only be offered along with condoms, comparing the use of microbicides alone to "wearing a bulletproof vest that's 50 percent effective...If you wear a bulletproof vest that's 50 percent effective, I mean would we go and ask someone to shoot you in the chest?...Use condom at all costs."

Several providers suggested that, given their partial effectiveness, microbicides should only be made available along with condoms to stress the method's limitations.

"40 percent is bad... But, you know, I think that one must be upfront with patients about that fact and really stress that this can only be used in conjunction with a condom, I mean unless it's absolutely impossible, then it can't be relied on. But I mean I would hope that you would be able to improve on that."

-Public health physician

A few policy makers and providers expressed concerns about the potential legal and political repercussions of introducing a partially-effective product. One public health manager worried that promoting use of a partially-effective microbicide might backfire on providers, who could become perceived as negligent for promoting a product that people use yet still become infected.

Finally, while some policy makers and providers were asked to comment on the "prevention equation" described in the introduction above, respondents had little reaction to this concept (that a less effective prevention method used more consistently could have a greater impact on preventing infections than a more effective method used less consistently), and in general the interviewers did not probe. Despite lack of data in this area, it is worth noting that it was not a concept that seemed to resonate with respondents. As stated previously, respondents expressed broad support for microbicides in light of the devastation of the HIV/AIDS epidemic, the vulnerability of women to infection, and the recognition that condoms are not used widely or consistently. The argument presented by the "prevention equation" appeared to contribute little to developing this support; this may be because it was not well understood, or because such evidence was not needed in this context.

\section{Who should/would use microbicides?}

Responses varied by and among respondent groups to the issue of the most appropriate and likely users of microbicides. Community-level respondents suggested that microbicides would or should be used by people of different ages, including very young girls and older women and men, suggesting that every person who was sexually active would be an appropriate potential user. While some policy makers and providers concurred, others felt that access should be restricted to what respondents defined as "high risk groups," which in most cases included most individuals at risk of infection, with the exception of young people.

\section{a. Range of potential users}

Respondents thought that a wide range of people could be potential microbicide users. Community members suggested that women of all ages and even children from a very young age should have access to microbicides because of their vulnerability to sexual abuse. At the same time, some suggested that 
older married men and women should use microbicides because they are still sexually active; because older men might have sex with younger women; and "because our husbands sometimes will also have a feeling to do something with us." A number of focus group participants thought that married persons would be likely to use microbicides because they were not in a position to negotiate condom use. Some community members thought that women and men who wanted to have children would be particularly interested in using microbicides if they allowed conception while preventing disease.

While many community respondents assumed a quite inclusive stance toward potential user groups, some women in focus groups saw sex workers as among the most appropriate users of microbicides. Sex workers were perceived to have unprotected intercourse with many different men in the course of their work, which practice was understood as conducive to the spread of STIs. Several participants in a focus group of nurses wanted to know whether HIV-positive clients or clients with other sexually transmitted infections would be able to use microbicides.

Data also suggested that providers tended to approach the subject of who should use microbicides somewhat differently from other respondents. They were more comfortable categorizing appropriate microbicide user groups according to risk, usually based on medical history, particularly history of STIs, and those who were unable to negotiate condom use. Providers tended to cite the broader range of risk factors for HIV such as number of sexual partners, ability to negotiate prevention options, and/or the dynamics of sexual relationships rather than characteristics such as age or marital status.

Other providers proposed limiting microbicide access to what they defined as "high-risk" groups. Yet when asked to clarify who they considered to be "high-risk," providers generally listed the same groups of individuals suggested by community members, adding individuals such as those with a history of STIs, HIV sero-positive individuals, commercial sex workers, those with latex allergies, and youth. A few providers felt that only those who were screened and found to be "high-risk" should be offered microbicides, saying that the method should be considered a "second line measure and not as a part of the front line intervention," offered only to those who have defined risk factors.

\section{b. Youth as potential users}

There was considerable support among community members, including youth themselves, for young people to be among the main users and beneficiaries of a future microbicide. This was based on a number of reasons - they are the most sexually active, do not use condoms, and are the most vulnerable to unplanned, unprotected, and coercive sex. Youth (defined by the community members as between 12 and 30 years of age) also were not "getting it" (that is, not understanding the serious nature of the epidemic), and they saw more youth as dying from AIDS than adults. One young woman stated, "Well, us youngsters are promiscuous, you'd never hear of an older person dying of AIDS. It's more prominent on us, so we have to use this method." Because focus group participants perceived that the sexual debut of youth was occurring at a very young age, they said there should not be age restrictions on microbicide users.

One policy influential stressed that adolescents should have access to microbicides, noting that children 12 to 14 years old "are having sex because of poverty...You have to have this readily available for those girls." Some providers were also willing to include youth among potential users, recognizing the epidemic rates of STIs among this group. There were policy makers and a few providers, however, who were reluctant to offer the option of microbicides to youth, saying that youth would not have the ability to comprehend the implications of partial effectiveness and that it could undermine recent gains in condom 
use among young people. Finally, a national policy leader stressed the important role a microbicide product could play for young women given the power dynamics present in many sexual relationships:

"That 10 percent of girls who are having sex are the ones who are where the man is most likely to not allow them to use... a condom... and so providing them with a technology that is outside of those sexual dynamics could be very helpful."

—National policy informant

A troubling finding was that the possibility of young children being raped was frequently raised by community women during focus group discussions. Several community women and men thought that there should be no age limit set for users of microbicides and expressed this through an acute sensitivity to the possibility of children five years old or younger being raped. "[Microbicides] shouldn't have an age restriction...even if a young child gets raped, with the substance applied...they can get protected from infections."

\section{FINDINGS RELEVANT TO THE COMMUNITY}

Issues of greatest importance and relevance to community members centered on concerns that impact people's daily lives — rape, violence, and partner relationships — and how microbicides might affect them. Discussions focused on whether there is a need for use without a partner's knowledge and whether this would be possible; pros and cons of partner involvement; how the characteristics of microbicides interact with sexual practices and beliefs; and how experience with other intravaginal products might affect use of microbicides. This section covers what respondents, primarily community members, described and what they perceived to be desirable and undesirable product characteristics, including serious concerns about whether microbicides might harm women's ability to become pregnant. It also presents approaches suggested by all respondents to develop support for microbicide use at the community level.

\section{Rape, violence, coercion, and unplanned consensual sex}

Community respondents described and discussed a range of situations in which microbicides could be used. A predominant theme was the need for a product that would be long-acting and could be inserted before leaving the house as a routine practice in case something unexpected or unplanned happened that would expose them to risk of HIV infection. The most common concern was about rape, which was discussed at length. Other situations cited were those where a woman might have unplanned but consensual sex, and in which a man might attempt to infect them intentionally, whether through rape or deceitful consensual sex. It should be noted that the themes of rape, coercion, and unplanned sexual intercourse were not included in any of the research guides, but emerged spontaneously as major concerns raised by women in all community focus group discussions, a few men in focus groups, and a number of individuals interviewed at the community and policy-level. Interestingly, only one provider discussed the issue of rape. Most raised the risk of being raped as a potentially important application for microbicides, and as a reason to support microbicide use on a personal or more widespread level. ${ }^{*}$

\section{a. Rape}

Issues of sexual assault, including rape, while not directly probed for in this research, emerged strongly as key concerns of community members across age and socioeconomic status. FGD participants, as well as several national policy makers and policy influentials, recognized that women, adolescents, and (as previously noted) children, were frequently at risk for rape or coercive sex. One policy maker, in

\footnotetext{
* The issue of rape in South Africa has been studied and received substantial attention in media and public discourse, which could partially explain the high recognition and frequency of spontaneous reporting of this issue among respondents.
} 
recognizing this as an important potential use for microbicides, was troubled by the reality in which women need such a product in order to protect themselves from rape or coercive sex:

"Indeed in cases where the sex [is] without consent, [a microbicide] is something that you can have in there and no one would actually know about it and it would be protective for the female. Of course, I hate it that women have always to think about whether they are going to be sexually abused, assaulted, et cetera, but in reality that is what's happening so one has got to be aware...if the occasion arises that you are forced to then you know at least you've got some chance of surviving."

-National policy influential

Many female respondents and some providers conveyed desperate feelings about the risk of rape. Several women in FGD talked about "surviving" rape without HIV infection, anticipating or assuming that microbicides would afford protection for an unspecified, yet lengthy, period. This possibility of regular use of a microbicide was suggested by a number of participants. One woman said she would "prefer that it's used all the time, it could so happen that one gets raped." Women talked about applying "the cream" as part of their daily routine in order to leave their homes prepared for any eventuality. As previously stated, they also talked about using microbicides to protect children from infection in the case of rape, suggesting the prevalent fear of sexual violence at the community level. During an interview, a community member suggested that women "should voluntarily use it [microbicides] because they could be raped anywhere." Reflecting the scope of concern and risk, a national policy maker stated, "I mean even an 80-year-old can be raped at any time." A young male focus group participant also said, "I wish it [microbicides] gets applied all the time because one wouldn't know if they [women] could get raped."

Women were very enthusiastic about the potential of having something that could offer protection in the perceived high likelihood of rape.

"I was going to support the cream (i.e. microbicides) that will protect us from rape situations, because I will never get infected with a disease when I apply the cream."

-Woman (26-45 years), informal settlement

However, as this quote suggests, in their enthusiasm for a solution, many women seemed unconcerned about the issue of partial effectiveness. This perception reinforces the concerns expressed by some providers and policy makers about the implications of introducing a partially effective product without sufficient information about the product's limitations, particularly given the level of desperation for additional prevention options, as reflected in the discourse on rape.

\section{b. Deliberate infection}

The idea that HIV-positive people deliberately infect other people heightened community members' feelings that availability of microbicides should be a priority. Women could use the product to protect themselves against anyone who might be trying to infect them through rape or deceit about their HIVstatus. They said that "the cruel ones," those that know they have the virus, deliberately spread it by sleeping with everyone because they "tell themselves that they won't die alone." Both women and men in focus group discussions voiced concern about deliberate infection.

"I see it as very helpful because some people commit rape in order to spread the disease."

—Woman (18-25 years), informal settlement

"If it could be 100 percent effective, women will use it a lot, because there are AIDSinfected men who rape women, so a woman would walk in the streets knowing very well that she is protected even if an AIDS-infected person would rape her."

-Man (26-45 years), homeowner

Paving the Path: Preparing for Microbicide Introduction $\mathbf{2 6} \cdot$ Qualitative Study Report 


\section{c. Unplanned consensual sex}

Many female community members viewed microbicides as affording protection from infections in multiple high-risk situations, including many in which sex might not be anticipated. Many assumed that or asked about whether the product would stay in place if they inserted it before they went out for the evening. Respondents indicated that they would want to apply microbicides before going out in case of unexpectedly meeting their boyfriend, or before going to parties in case of meeting someone and having sex. A female focus group participant described such unplanned sex that occurs in the taverns:

"Because in most cases that's where most people meet [taverns], get drunk, and get horny, and have quickies in the toilets."

-Woman (26-45 years), renter

A provider echoed community members' views of the need to be able to insert the product ahead of time in case sex occurs. She articulated the challenge in applying a product immediately before unplanned sex, describing the context of housing without privacy.

"The problem is that you won't know you never know whether you're going to have sex or not. People stay in small rooms all in one room where they can't even say 'I'm going to the toilet quickly' and then put it [microbicides] on. You know? How long must you wait in the toilet..."

-Nurse

\section{Partner involvement and covert use}

The possibility of covert use or use without a partner's knowledge was an early premise of microbicide development. Given that covert use may not be desirable or even possible with all products under development, focus group discussions and interviews probed for perspectives on covert use and partner involvement. A range of opinions emerged from these discussions, some supporting the need for covert use, some questioning the feasibility of covert use. In addition, many respondents felt strongly that involving partners in microbicide use was both ideal and feasible in many circumstances.

\section{a. Partner communication and involvement}

Both male and female community respondents expressed strong support for open communication about using microbicides. Both men and women indicated that some men could be compelled to agree to use microbicides with their partners once they understood that it protected against STIs and HIV. Women suggested that certain types of men, such as men who care about themselves and their partners, are more likely to want to be involved in microbicide use.

"If a man loves you, he shouldn't have a problem with it. This would need the cooperation of both partners."

-Woman (18-25 years), renter

Women believed that men who understood the gravity of the AIDS epidemic because they had personally witnessed the effects of AIDS on the community would be most likely to support their partners' microbicide use. Men also perceived that their partners were likely to have a positive attitude toward microbicide use if men introduced the subject. Some even suggested sharing responsibility for use and that partners should take turns putting the product into the woman's vagina.

Many women felt that communicating with their partners about microbicide use was both important and feasible. One sex worker felt that agreement on the importance of microbicide use could be reached through open communication and adequate information to alleviate suspicions. Some women stated that men could be reasonable, caring, and open to negotiating microbicide use. They felt that, at the risk of being told no, they could propose the method to their male partners to see if they "would like it or not." 
Some male and female FGD participants expressed the importance of partner involvement, stating that "partners can communicate and the other should make a man aware of what they are using and state that it's to prevent infections." The importance of expressing the reasons and intentions for microbicide use were frequently discussed as the proactive way to dispel mistrust and negotiate use.

"I would tell him that I'm not seeing anyone, I'm only preventing from this existing disease, let's just use the cream."

—Woman (26-45 years), informal settlement

In addition to communication between partners, female participants also suggested that information acquired from peers and men's communication networks would be important to support men's willingness to use microbicides once proposed. One woman said that this would be important because sometimes "men did not want to listen to what women had to say." Another participant from the same group suggested that workshops consisting of both men and women should be held to facilitate partner dialogue and better prepare men to express themselves in the presence of women. A community leader echoed these women's views, supporting male involvement and partner communication:

"The best way of involvement is through education. Knowledge is power. They shouldn't get to know about it from hearsay or see it being used at home behind their backs. They might think that the woman is implying that he is unsafe."

-Community informant

Despite extensive discussion about the fact that men and women do not trust each other, trust was commonly reported as necessary for effective partner communication. Respondents felt that trust would enable women to negotiate microbicide use with partners, which would be preferable to covert use.

"It would be nice if partners could understand, such that we apply the gel in front of them, if partners could trust each other as opposed to applying it on the side."

-Woman (26-45 years), renter

\section{b. Covert use}

While most community members conveyed a strong desire for communicating with and involving partners in microbicide use, many felt that, in the context of certain relationships, covert use would be a necessary alternative. This was particularly true where there was a lack of trust between partners, where women lacked the power to negotiate the product's use, or where they feared the repercussions of communicating with partners about microbicide use. Other respondents suggested that women should have the right to privacy and to choose whether to inform their partners that they are using a microbicide.

Men's likely opposition to microbicides was the primary reason cited for covert use. Female community members said that they would use microbicides without their partner's knowledge if a male partner was "difficult," was generally opposed to using prevention methods, or if they suspected that their male partners had other partners.

"Our boyfriends are stubborn and they sometimes force themselves on us and take offence at the suggestion of safe sex. They take that as an implication that they might have AIDS forgetting that one is trying to protect them as well. So, this would be very helpful."

—Woman (26-45), homeowner

Several women suggested that covert use would be a more feasible option than overt use because of women's lack of power in sexual relationships.

"I think it will be difficult for men to use it, because men don't want women to have a say especially regarding sex."

-Woman (26-45 years), homeowner

Paving the Path: Preparing for Microbicide Introduction $\mathbf{2 8} \cdot$ Qualitative Study Report 
Some, such as this community nurse, speculated that covert use allowed women to avoid dealing with men's potential suspicion at a women's suggestion that the couple use a microbicide.

"Men ... might take offense at not being trusted when the wife is using it and might also think the wife is two-timing them. There must not be a secret between a man and a wife, especially between a girl and a boyfriend."

-Nurse

Drawing analogies with contraceptives, some women felt that covert use could afford women protection while men would remain unaware of it.

"...If you dare tell a man that you are using that method it will poke them causing discomfort and everything else you can imagine. Yet, if you keep quiet about it, you'll never hear a single complaint. So that's how men are."

-Woman (26-45 years), homeowner

"I'm telling you this gel will work because it is inserted inside unlike the condom they are lazy to use, because they don't want to tear them. This is inserted and enters the system and men will not feel what's going on inside, because they felt nothing on the caps we used, we told them nothing about it, and they did everything."

- Community leader

Providers, policy influentials, and policy makers also recognized the importance and utility of covert use. As one doctor in the public health sector noted, "Everybody wants to have some kind of secret, and some kind of privacy, you know." Policy makers and key policy influentials expressed similar sentiments and felt that a method which was both "self-controlled" and "discreet" would be attractive to women.

Independent of the reason why women would choose not to disclose microbicide use, some community members saw it as an issue of woman's choice.

"It will be a woman's choice not to tell their partners about it, because it is for preventing herself."

—Woman (26-45 years), homeowner

\section{c. Limitations and potential repercussions of partner communication and covert use}

Despite strong support for partner communication, as well as wide recognition of the benefits of covert use, both men and women expressed some reservations about the feasibility of covert use given the description of potential product characteristics.

"Okay, if my partner doesn't want to use either, a condom and this gel, will he not be able to feel that I have some substance applied underneath?"

-Woman (26-45 years), informal settlement

"If someone has used it, definitely it is going to be easy to identify that there is something inside because this is like a gel as you have explained. There is no way someone can hide it."

—Man (18-25 years), informal settlement

Several providers, policy makers, and key policy influentials were also skeptical about the notion that a female-initiated method did not need to be negotiated and that microbicides could be used covertly. Similar to what was discussed among community discussion groups, two doctors in the public sector also felt that incorrect application or the microbicide's texture or smell would make invisibility, and thus covert use, impossible. A national policy key influential and others asked if covert use would even be 
feasible if microbicides came as a "thick cream" and "the guy pulls out and his penis is full of that thick cream ...He's going to ask questions."

Given reservations about the possibility of covert use, several respondents voiced their doubt, ambivalence, and even fearfulness about the potential negative repercussions of both suggesting microbicide use, as well as being discovered using a microbicide covertly. Several female FGD participants feared that suggesting microbicide use to male partners could introduce or exacerbate friction among couples where there already was mistrust; it could also introduce suspicion or lead to accusations from men, such as being blamed for male impotency. Women also discussed fears of abandonment and mistrust as a result of microbicide use, especially if men were to equate the "wetness" resulting from microbicide use with infidelity.

Echoing women's concerns, national and provincial policy makers and key policy influentials discussed the possibility of conflict, abandonment, or violence. As a national policy maker noted, "You'd be kicked out of the house if the other party realized you're using something."

A female FGD participant suggested that a woman could still use it covertly, even if the man detected something, because she could deny the product's intended function or attribute lubrication to other factors.

"For instance, we do use things like vaginal tubes (suppositories) and they know it. One could simply say it's to clean oneself and they wouldn't have a problem."

—Woman (26-45 years), homeowner

\section{Implications of local sexual and intravaginal practices}

A woman's comfort with the use of microbicides and her perceptions of the feasibility and potential ramifications of microbicide use are likely to be informed by her experience with intravaginal products as well as sexual practices and cultural norms. The fact that a woman must insert the product in her vagina and the potential impact of microbicides on sexual relations were cited as potential barriers to microbicide use. Respondents were thus asked directly about intravaginal product use, also probing for information on sexual practices, norms and beliefs that might influence the use of microbicides.

\section{a. Intravaginal product use}

There were wide-ranging and contradictory views about women's experience and comfort with using vaginal products. Women in focus groups spoke about their familiarity with vaginal products and felt comfortable with the idea of using a vaginal product. Most women and several providers stated that women were already using tampons and vaginal creams for thrush.

"We won't be against it because we are already used to using ointments. Men would see it otherwise. They're not even bothered in using lotions, and with us we are already used to such even with vaginal thrush for instance, we sometimes request getting the cream as opposed to pills due to its fast effectiveness."

-Woman (26-45 years), renter

When asked if women would be comfortable using a vaginal method, some providers and several policy makers gave conflicting answers. A provincial policy influential noted that women already use a number of lubricants or vaginal methods and a microbicide would not be "foreign" or "seem very scary." Providers from both the public and private sectors supported this view. However, a provincial key policy influential felt that methods requiring vaginal insertion would be problematic and that women sometimes delay treatment for thrush because vaginal methods are not attractive. A key informant from an NGO concurred by stating that women are not comfortable with "inserting things into their vaginas." Another

Paving the Path: Preparing for Microbicide Introduction • $\mathbf{3 0}$ • Qualitative Study Report 
skeptical reaction came from a policy maker in the field of HIV/AIDS, who said that, in her experience, women were reluctant to insert creams into their vaginas. Despite this, she still felt that the microbicide would be important in its potential to offer women more choices.

\section{b. Wetness and "dry sex"}

Respondents at all levels discussed at length the effect of "wetness" on microbicide use and sexual practices. The concept of "wetness" generally was mentioned in relation to the added moisture that the microbicide could present during sexual intercourse. This was discussed, for the most part, with three levels of meaning: a) a woman's vaginal wetness implying infidelity (i.e. she had been with another man), b) the preference of men for a "not wet" or "dry" vagina for increased sexual pleasure, and c) the association of "wetness" with sexually transmitted infections (STIs).

Given popular assumptions about vaginal lubrication and its association with disease and/or infidelity, several policy influentials suggested that the introduction of microbicides should be accompanied by awareness programs about women's anatomy and natural lubrication so that women could better address accusations associated with increased vaginal lubrication. One nurse spoke of the need to address potential client concerns about wetness and lubrication during counseling. She predicted, "Some people would come and say, 'My boyfriends are complaining that I'm wet using that gel."'

These concerns about "wetness" were often discussed by policy makers, policy influentials, providers, and some community focus group participants by referencing their experience with negative reactions to the wetness caused by hormonal contraceptives. A national policy maker mentioned that while the medical community had played down these side effects, women frequently complained of changes in vaginal lubrication associated with contraceptive use and their partners' responses to these changes. In a focus group of nurses, several participants also reported that women often express concerns with the vaginal wetness associated with injectable contraception.

\section{Infidelity}

Study respondents, both male and female, most often equated being wet before intercourse (described as ubumanzi in Xhosa), with infidelity and "sleeping around." The mistrust that could ensue was mentioned by men and of particular concern to women in focus groups.

"I know there is foreplay before one gets sexually aroused. Now this gel gets put inside and there could be some misunderstanding when the man finds the vagina wet already. This would create mistrust and one would think his partner had sex with someone else."

-Male taverner

While men spoke about natural wetness due to foreplay and sexual arousal, they were concerned that it would be difficult to distinguish whether a woman was wet due to the microbicide or wet due to having had sex previously with another man. Male focus group participants conveyed their concerns and sense of mistrust related to wetness, despite acknowledgement that a woman might be wet due to sexual arousal.

"Men have certain tendencies which could result to them not being interested in this method used by women. Men always have priorities when coming to sex. We know that women's vaginas are always moist. There are men who could get put off by the fact that it's wet and think they had sex with someone else. As much as we are aware that when a woman feels pleasure sexually she gets wet, so the gel could make a woman even wet [ter]."

-Man (26-45 years), homeowner 
Women in focus groups also were concerned that their male partners might interpret the presence of added wetness due to the microbicide as a sign of infidelity or promiscuity. For instance, one woman expressed anxiety:

"When he arrives he will find that you are already wet and think that you've already slept with another man, causing arguments."

-Female taverner

\section{Sexual pleasure and "dry sex"}

Although in southern Africa a preference for dry sex to increase sexual pleasure has been reported, ${ }^{2,3,11}$ most focus group participants were not familiar with the practice of dry sex as defined by the insertion of various drying agents into the vagina before sexual intercourse. ${ }^{*}$ Similarly, most policy makers and key policy influentials and some providers were unsure whether the practice of "dry sex" was widespread in South Africa or admitted they were not well informed about the issue. One public health doctor stated that he had read and heard about the practice but never had a client who reported using any drying agents.

National policy makers felt that, although "dry sex" may not be an issue among teenagers, "myths" about the "dry issue" are "rife" among youths and adolescents.

Nevertheless, community key informants and women in focus groups did speak about men's preferences for the vagina to be dry or "not wet" during sexual intercourse, implying that wetness associated with microbicides could be perceived as negatively affecting sexual pleasure. Women indicated that men preferred them to be dry and tight "like a virgin."

A female homeowner suggested that microbicide developers needed to come out with a method that was tailored to men's sexual preferences and suggested a method that was "similar to a face cream and that evaporated quickly" so as not to increase wetness. The amount of microbicide to be used was of significance within the context of wet sex. Young women from the informal settlement spoke about using small amounts of the microbicide to avoid additional wetness and the associated problems with being too wet. They spoke about inserting specific amounts of the substance, just enough "to form a wall," but not too much to cause one to be "too wet and slippery."

Despite notions of men's preference for a dry vagina, some respondents indicated that women might welcome "wetness." A provincial policy influential felt increased lubrication may be advantageous and attractive for sex workers as they frequently experience vaginal dryness. A participant in a focus group of nurses also felt that women who experience vaginal dryness when using certain contraceptives also might find microbicides attractive. Some women complained that men were not always sensitive to their needs with their preference for " $d r y$ " sex.

A young woman poignantly pointed out that the issue of wetness was ultimately secondary, and that it was not about "dry sex or wet sex, but about safe sex."

\section{Wetness and STIs}

Several providers, policy-level respondents, and community members also referred to "wetness" in association with STIs. One policy maker stated that many youth associate wetness or "discharge" with infidelity or disease. Similar to associations with infidelity, wetness as a symptom of an STI was negatively perceived by most respondents, including some community members who were interested in understanding if one could differentiate between discharge and wetness as a result of microbicide use. A nurse discussed the importance of informing clients about the degree of lubrication or wetness to be

\footnotetext{
* These findings are consistent with another study on intravaginal practices in Khayelitsha, Cape Town, a large township not too dissimilar to Langa. In this study, dry sex was rarely reported at only 1 percent. (Myers, Denny et al., 2003).
} 
expected from microbicide use and explaining the difference between "normal discharge" and heavy itchy discharge, indicative of possible STIs.

\section{Product characteristic preferences}

Study respondents discussed a range of possible microbicide characteristics that they would consider positive or negative. Despite great variation in personal preferences, most participants believed that regardless of eventual product characteristics, there would be a considerable market and need for the product.

In terms of physical properties, most of the characteristics discussed below emerged as questions or in the course of discussion about the product's potential uses. Among the physical properties discussed were smell, messiness, stability of the product for storage, duration of effectiveness, and the product's adherence to the body in relation to bodily functions. Some participants also discussed the design of the applicator, mode of delivery of the product, and effectiveness in preventing other STIs and pregnancy.

\section{a. Physical properties}

Both men and women in focus groups spoke about a range of preferred microbicide physical properties, related to texture, color, and smell. Some felt that an unpleasant smell would be unacceptable and would discourage people from using the microbicide. Many were concerned with the texture or "messiness" of the product, suggesting that the product should not be too greasy or too liquid in its consistency. One provider wanted to confirm that microbicides could safely be used along with condoms, without having "an effect on the lubrication of the condom." A national policy maker was one of few participants who noted that ideally microbicides should quickly reach body temperature in order to most resemble a woman's natural lubrication.

As noted when discussing the potential uses of microbicides in case of rape or unplanned consensual sex, duration of effectiveness and time to effectiveness were discussed at length in all respondent groups. Numerous reasons were also given for wanting the method to last for long periods of time. Women in focus groups suggested that the microbicide should last for 24 hours and form part of their daily routine. Similarly, a group of young men envisioned a microbicide that would be as easy to use as a "roll-on [an underarm deodorant] that lasts from when it's applied in the morning," and where "it stays dry all the time, because if it causes wetness, it will make one lose interest during intercourse." Some community women indicated that microbicides should be like the contraceptive injection, which is administered every two to three months.

Most policy makers and providers also felt that microbicides should be both quickly effective and long acting. A provincial policy maker suggested it would be preferable if microbicides were effective for multiple sex acts. However, several respondents in a focus group of nurses suggested it might be better if microbicides were only inserted immediately before sex and then washed off afterward to avoid "being wet or causing skin irritations." One national policy maker was concerned that if it was effective for an extended period of time it might "start interfering with the normal function of the body."

The importance of product stability was mentioned by several policy makers and providers. They indicated that microbicides should be stable at a variety of temperatures and should not require

\footnotetext{
* It is not surprising that participants likened the duration of action to contraceptives, a familiar reference point, as contraceptives form an important part of women's reproductive experiences. Three-quarters of South African women aged 15 to 49 have used a contraceptive method, and 61 percent of sexually active 15- to 49-year-olds currently use some form of contraception.
} 
refrigeration. Additionally, both male and female focus group participants raised questions about how well the product would adhere to the body and what happened to the product after it was inserted. This in turn was linked to everyday bodily functions such as washing and urinating. One woman asked, "How does it come out, does one have to urinate to get rid of it?" Similarly, a group of men from the informal settlement were particularly concerned as to what would happen before and after urinating, and if women could use the method while they were menstruating. Lengthy conversations ensued around how urination could influence the method's effectiveness. Men felt they needed assurance that the method would not be removed during urination.

\section{b. Applicator and mode of delivery}

Similar to other characteristics already discussed, some participants had varying views on how microbicides should be delivered into the vagina. Since focus group facilitators and interviewers showed focus group participants and interview respondents an applicator similar to that currently used for Carraguard $\AA$, most participants who commented on this issue reacted to this applicator, with some suggesting alternative modes of delivery.

Some women in focus groups expressed concern about the shape and phallic appearance of the applicator and felt that it was "too sharp" and would be painful and difficult to insert. "One focus group participant commented:

"It's not attractive to look at it. Honestly, even if one doesn't mind sex and a penis, it looks like the shape of a penis, it does, and it doesn't interest me at all. One other thing, it's made for women, its shape gives one the impression that women want sex all the time."

—Woman (18-25 years), renter

They also suggested that it should be designed differently, "similar to the suppository" or like a tampon. Nurses in the public health sector and several provincial and national policy makers had similar suggestions and felt that the applicator should be "friendly to the user." A national policy influential felt the applicator looked like a "clinical gadget. It's frightening." Another looked at a sample microbicide applicator and said:

"This looks like a horrific gadget, but it certainly looks like a piece of medicine."

-National policy influential

The actual mode of delivery became a topic of detailed discussion as female focus group participants suggested different mechanisms of administration, such as a pessary or suppository versus an applicator, or oral ingestion. In another discussion group with nurses, one participant stressed that it should be easy to insert whether a woman lies down or lifts up one leg. Another doctor who commented on the issues recommended that the applicator should be for a single dose rather than a tube or multi-use applicator that could potentially be shared by multiple women, thereby creating a risk for infection.

\section{c. Scope of protection: HIV, other STIs, and pregnancy}

Some microbicides may have contraceptive properties or offer protection against other STIs, while others may not. Policy leaders, providers, and community-level respondents differed in their views on the scope of protection that they would like microbicides to have. Some were able to clearly separate the issues of HIV/STI prevention and pregnancy prevention, while others saw them as inextricable.

\footnotetext{
${ }^{*}$ It should be noted that the edges of this applicator are not sharp, and that respondents are referring to the pointy shape of the applicator. See photo on page 15.
} 
Community members had mixed reactions to the desirability of contraceptive properties. Women tended to prefer that microbicides not be contraceptive, while more men preferred that microbicides would have contraceptive properties. One male taverner said:

"If you want her to fall pregnant, then you discuss with her not to use it. Because should I meet someone at a party and sleep with her, and then she comes to my home the following week to say she's pregnant."

-Male taverner

Another added that having to worry about dual methods would be too complicated. "I don't want to use a condom [and] I still don't want her to fall pregnant when she's using this gel." However, some men recognized that women would not want a microbicide to prevent pregnancy. For example, a young man felt that women would find a non-contraceptive microbicide more attractive as "they enjoy falling pregnant." Some men also preferred a non-contraceptive.

"[It's] very important with regards to preventing disease. If it will prevent pregnancy as well and make us not have children, it won't be appropriate."

-Man (26-45), informal settlement

Provider experiences with managing and treating large numbers of people with HIV and other STIs shaped their perceptions of the most pressing and immediate prevention needs; they tended to see contraceptive needs and disease prevention needs as two separate issues. Several providers were not convinced of the need to have a microbicide with contraceptive properties given the existence of other contraceptive options. When asked, "What sort of advice would you give a client in relation to contraception if microbicides do not prevent pregnancy?", a few providers even appeared confused by the association of contraceptives and microbicides. One doctor responded by asking, "Is this a trick question?" The provider then went on to elaborate that she did not foresee a problem as long as the microbicide did not react with a woman's regular contraceptive method. Only a few providers felt that dual-protection characteristics of microbicides would be advantageous in the sense that they could facilitate consistent and ongoing use.

Provincial and national policy makers and providers seemed ambivalent about recommending microbicides for pregnancy prevention if they were proven only partially effective. ${ }^{*}$ One private doctor said he would recommend it to his clients for both purposes if the contraceptive effectiveness of microbicides equaled that shown by other methods, such as injectables. Several policy makers felt that a microbicide with dual protection properties (HIV/STIs and pregnancy) would be a beneficial addition to family planning programs. One national policy maker explained that one reason it would be advantageous was the difficulty of motivating clients to use both condoms and injectable contraceptives.

Given the immediacy of the HIV/AIDS epidemic and the current availability of acceptable and effective contraceptive methods, several respondents felt it would not be necessary for microbicides to provide protection against both pregnancy and HIV. One national policy influential felt that, while it would be ideal for a microbicide to prevent pregnancy, finding a barrier to HIV "is a priority" and should be addressed first.

By contrast, a few policy makers felt that clients may not find a microbicide that prevents pregnancy more attractive. A representative from a nongovernmental organization suggested that among certain sections of the population, particularly sex workers, there was a particular need for HIV prevention rather than pregnancy prevention measures. Another national director suggested that the availability of both

\footnotetext{
* Providers were not told that microbicides would be partially effective as contraceptives-they assumed this would be the case since first-generation products are likely to be partially effective for HIV prevention.
} 
contraceptive and non-contraceptive microbicides could lead to confusion and discord among women and their partners.

\section{d. Infertility concerns}

Both men and women in focus groups were concerned about a microbicide's possible short-term and long-term impact on fertility and child bearing. These concerns emerged spontaneously as respondents' explored possible side-effects from microbicides. Women ascribed male partners' and other women's possible reluctance to use microbicides to a fear or belief that it would have a negative impact on fertility. One woman stated, "Our fear would be the side effects, like making one unable to bear children." Many men were equally concerned that the microbicide might impact on fertility and a woman's ability to bear children. These concerns were not surprising considering the importance placed on child bearing in many communities.

Women and men were also concerned about the possibility of infertility associated with frequent microbicide use. Indeed, several community members pointed out that microbicide use might be falsely associated with infertility. A young woman from the informal settlement suggested a married woman using microbicides might be accused of being infertile if she did not become pregnant, and other women from this area and young women renters echoed these concerns and vividly described the social cost of infertility: "And [when] one can't have children, then we are chased away."

In the event that microbicides did not prevent pregnancy, both men and women expressed concern about the effect of microbicide use on fetal health. A key informant and some community members felt that microbicides should not only be safe to the user, but also should not harm the fetus.

\section{FINDINGS RELEVANT TO SERVICE DELIVERY}

The research addressed several issues related to microbicide introduction with important implications for service delivery programs and providers. Respondents discussed the challenges of meeting counseling needs with a partially-effective, user-controlled product, and approaches to ensuring informed choice. They also addressed how microbicides might fit into the current mix of HIV prevention methods, and considerations for presenting microbicides within a hierarchy of prevention options. Finally, discussions focused on channels through which microbicides might be distributed in both clinical and non-clinical settings, including approaches to ensuring adequate information and counseling while promoting broad access and choice.

Perceptions of policy makers and key policy influentials, and to a lesser extent providers and community members, were shaped by their previous experiences with the introduction of reproductive health innovations. Alluding to experience with introduction of technologies like the female condom and programs such as prevention of mother-to-child transmission (PMTCT), providers in particular emphasized the value of early involvement and information before offering any new product or approach.

"Clinics and health providers need to be informed before the product hits the market. I think that's what people like-I think first of all, rather than waiting until we get circulars coming around, but it doesn't have the same effect if we have somebody in front of you and showing you, this is the product, this is the use, and this how we're planning to do it... and that information is available. It makes it so much easier."

—Public health doctor 


\section{Counseling and informed choice}

Counseling was considered an important element in ensuring that potential users are knowledgeable about product use and fully aware of the implications of partial effectiveness so that they can make informed choices. Policy makers and providers discussed a range of complex issues related to presenting microbicides in the context of an HIV risk-reduction approach.

Almost unanimously, policy makers and policy influentials felt that clients should be informed about the safety, effectiveness, contraindications, and side effects-information considered essential for a woman to make an informed choice about whether or not to use microbicides. One policy influential stressed that only with a full understanding of partial effectiveness can women make informed decisions. A policy maker spoke of the importance of "full disclosure" in presenting options. As such, many providers and most policy makers supported offering the option of microbicides among a broader range of prevention methods, with the belief that greater choice would reinforce prevention and decrease the incidence of HIV transmission to save lives. However, a few providers talked about the importance of choice, then went on to state that they would only be willing to offer clients the option of microbicides if they believed it to be appropriate, suggesting that informed choice did not have the same meaning for all providers.

Community members also asserted that they would need extensive information and education about microbicides. One community member interviewed, for example, said that users "will need to be educated first, and be given lessons on how to use it...I'd never use something with no clear explanation. It's important that I get taught about it, truly speaking." Another, a male focus group participant, emphasized this need in the recognition of the difficulty in making changes related to sexual practices.

"It's not a matter of getting used to something overnight when it comes to sexuality...It means I'll forget one day, but the following morning I'll wake up and realize. That's why I say the most important thing is to train people."

-Man (26-45), homeowner

When asked who should provide the necessary information, respondents at all levels repeatedly mentioned health care providers, community health workers, or people specially designated as "counselors." However, as many providers recognized, identifying who in a particular clinic should provide counseling can be difficult. A public health physician noted that, ideally, health providers in large clinics who deal with sexually transmitted infections should be responsible for introducing microbicides, while another public health physician felt that designated counselors should be hired at respective facilities to "take the pressure off the provider."

While aware of the value of counseling, several providers also were acutely aware of the difficulties of providing quality service, particularly in the public sector. In a focus group, nurses mentioned that clinics are often crowded and providers pressed for time.

"My problem is I wish I had more time to do what I'm doing. There's no time to sit with a patient. Language is a problem. If I have an interpreter sitting with me, maybe we can do much more. We don't have that here; we don't have enough staff for that."

-Public health physician

Given these difficulties, providers and policy makers stressed the need for provider training and regular updates. One physician suggested that everyone in the health clinic, not just physicians, should be trained in order to increase the impact of the intervention. A provincial policy maker stressed the importance of also involving community health workers in training so that may provide good counseling for their clients. 
A few respondents also saw community leaders playing a role in delivering counseling and accurate information to potential users. A community member interviewed initially agreed that health care providers should be the ones to do counseling, stating that "professionals are good even in explaining when one has never heard of it, for instance..." She later acknowledged that lay people could play a role, stating, "I'd like it to be handled by pastors in churches, because they are faithful people. Female pastors would be better ...they will be able to express themselves easily to other ladies."

\section{a. Counseling messages and approaches}

Again, policy makers' experience with other technologies, particularly the female condom, informed their understanding of the kind of counseling necessary for microbicide introduction. One policy influential stressed that good communication and counseling were both the greatest challenge to and the measure of success of introducing new health innovations such as microbicides. In addition to information on safety and side effects, respondents also mentioned that counseling should include information about how microbicides work and how microbicides might influence women's fertility. Policy makers also felt that counseling should address more general issues about women's sexuality and anatomy, including the changes of lubrication in a woman's vagina associated with use of microbicides to help minimize allegations of infidelity associated with an increase in lubrication or wetness.

Several policy makers mentioned the need to include men in counseling programs. A journalist said that educating men would help to create an enabling environment for their partner or partners to use the microbicide. It was also suggested that women need counseling on partner communication and how to negotiate microbicide use. In the words of a national policy maker in the public sector:

"Even if microbicides are coming, we need to empower women in terms of their negotiating skills, you know, for them to be able to start talking to their partners because this has come up several times with the female condom ... It's basically initiating communication, you know, to say that the act needs two people, it takes two to tango, for them to start talking about it."

—National policy influential

A private physician highlighted the difficulties in conveying complex ideas about prevention, particularly given his clients' limited knowledge of the concepts of germs or infection. He stressed the need to keep messages concise and "simple." A provincial director of a nongovernmental organization underscored the effort involved in crafting creative and effective counseling messages.

"You know, not just sort of assume or write it on a piece of paper and think that someone's going to understand it, you know, and obviously finding better words, like efficacy would be a bit \{pause\} just something that would make people feel clear in terms of what it is and what it is providing."

-National policy influential

\section{b. User-controlled methods}

One issue that emerged in the context of counseling needs and informed choice was concern over the user-controlled nature of microbicides, and the implications for consistency of use and continuation. Consistent with the doubts that providers often have about user-controlled contraceptive methods (such as condoms and other barrier methods and oral contraceptives), some providers interviewed emphasized their concerns that microbicides would not be highly effective in preventing disease transmission due to the possibility of discontinuation. When asked about the perceived disadvantages of microbicides, one provider responded, "The disadvantage would be the possibility of stopping the method." Other providers were concerned about the dosage and frequency of application, suggesting a lower likelihood of 
compliance with a user-controlled microbicide that required more frequent application. One private physician noted:

"If it's a monthly thing that needs to be taken, it's fine. You know once a month, but if it's a daily thing or three times a week, they're not going to be very compliant."

-Private doctor

Providers indicated that consistent use would depend on the nature of associated side effects, noting that it would be pointless to expect consistent use with microbicides if they had serious side effects.

Nonetheless, some providers spoke about how newly introduced products also face the burden of having to live up to client and provider expectations, and that criticism of new methods was not uncommon.

"Everything that is new is going to be criticized or it's not acceptable initially. It takes time because initially people wouldn't even think of the condom but now gradually for those that feel - know that, they can see that HIV/AIDS kills, they'll use it."

-Nurse

To overcome this perceived resistance to microbicides and to facilitate ongoing and consistent use, policy makers and providers emphasized the importance of comprehensive counseling and support, and equally their own need for support, including information and training so they can better meet the prevention needs of their clients.

\section{Integration into the hierarchy of prevention options and method mix}

Male and female condoms are frequently offered as part of a hierarchy of options that could help prevent HIV infection. For almost all providers, the concept of a prevention hierarchy or the relationship of microbicides to existing prevention methods and strategies emerged naturally during interviews and discussions. However, the views of providers and policy makers on how microbicides should be integrated into the existing method hierarchy varied. The majority of respondents emphasized that while microbicides were not the ideal product, they could complement existing, albeit limited, prevention options to reduce individual and community HIV infection rates.

Many providers and policy makers were enthusiastic and supportive of having alternative options; however, given microbicides' partial effectiveness, they were somewhat cautious about how to offer and position microbicides in relation to other prevention options so as to discourage or limit condom substitution.

"People want to get a product that they believe is going to protect them ... it's like you say, this is a method, it's not completely safe (i.e. effective) on its own, you have to use it with a condom, you know? ... people might think well, if I have to use this and the condom then like what's the - you know, why am I using it?"

-Provincial policy influential

A public health doctor stressed that while microbicides could be offered as an "extra weapon," the condom should still be considered the "health standard." Another advocated for offering microbicides, but only as a "complementary" to condoms, suggesting that dual methods—condoms and microbicidesshould be the approach.

"... I think the hard and fast rule is use a condom at all costs. I mean whether you are using anything else (or not)."

-Private doctor 
Other providers and policy makers recognized the cumulative risk reduction benefit of offering microbicides, even as stand-alone product.

"I think part of your challenge is that the $a, b, c$ approach is so linear or exclusive. It is abstain or be faithful or 'condomise' and I think that your communication needs to be structured so much more around risk reduction, overall risk reduction, and get people to understand the marginal benefit of a condom, the marginal benefit of using a microbicide and the cumulative risk reduction of multiple risk reduction strategies."

—National policy influential

Many policy makers and providers felt the products should be offered, but positioned together with the male and/or female condom, even if people choose to use microbicides alone, in an effort to continue promoting the most effective method but also to provide multiple options and reduce risk overall.

"So I think maybe you should-you can develop other methods and at the same time devise other ways of making sure that people know the condom is still the best. I think you can't only have the one and think that you're going to be okay."

-Provincial policy influential

A policy maker argued that informed choices and advocating for risk reduction messages were ideal but may not be realistic in the context of an overburdened health system. Sharing the views of other policy makers and some providers, a provincial policy maker was reluctant to predict that microbicides could be easily integrated into the spectrum of prevention methods without efforts to overcome provider biases against what would be perceived as an imperfect and complex method to offer.

"I guess [the] major obstacle against or blocking is general health workers...You have to kind of convince a health worker that it's going to be worth the effort to try and actually do something, where we have condoms and it's just easier. It's easier for [them] seeing 100 people a day to promote condoms. [As a health worker] why should I diversify my message and introduce something which could be effective, is not effective, could have side effects, can't guarantee it?"

-Provincial policy influential

\section{Distribution channels}

Study respondents and focus group participants at all levels discussed a range of potential distribution channels for microbicides. In recognition of the idea that products and services may be delivered outside of the clinical setting, and that the clinical setting may not be ideal for facilitating access, researchers probed for ideas about how microbicides could be delivered in a range of settings under varying conditions.

\section{a. Potential avenues/venues for introduction and distribution}

Community members, policy leaders, and providers articulated the need to balance a desire for widespread access to microbicides with the need for relatively complex prevention messages. While most respondents felt microbicides should be widely available, many also hesitated to endorse the distribution of these products in venues where personal counseling was not available, given the partial effectiveness of these products. There was also concern about ensuring the quality and safety of microbicide products when purchased in the non-health commercial sector.

Health facilities were most often named as the ideal venues for distribution. A young woman from the informal settlement felt microbicides should be available at clinics because "that's where we go mostly for such things and that's also where we get our contraceptives." The director of a national NGO agreed that microbicides should be available in the government health sector because women already went there 
for maternity and well-baby services, and providers also felt that microbicides should be available at health facilities. A public health manager suggested that microbicides should be available in family planning, maternal health, and VCT clinics because family planning clinics already offer comprehensive services, and a private physician felt that they should be available at local clinics, day hospitals, and GPs "because those are the people who see most clients."

A number of respondents suggested potential problems associated with distributing the product in the public health sector. If microbicides were distributed at public health clinics, for example, they would be associated with disease rather than health. In a few community focus groups, participants expressed suspicion that even if microbicides were to be distributed in the public sector, they might not be available to clients because the health service providers would take microbicides for themselves and "tell you it's finished with a 'for sale' sign outside." Others noted poor treatment by nurses as barriers to access. Building on this concern about the limitations of the public health service, a private physician mentioned that microbicides should be available wholesale for private physicians because there may be shortages in the public sector.

Finally, noting that people are not always comfortable in health service environments, one policy leader underscored that:

"[You need to] get a person that they can relate to, that they can feel comfortable talking about issues... If you allow service providers to be the main entrance for the product, I think you limit the chances of it being more effective.

-National policy influential

Building on this, a variety of additional venues accessible to both men and women were proposed by respondents at all levels: community-based organizations; chemists, supermarkets, and outlets at which herbal medicines are obtained; and at spazas (local informal shops) and shebeens (bars), particularly for men since they do not visit health facilities frequently. A woman in a focus group felt products should be found in "places we can reach without using public transport because clinics get closed ... A place that everybody can reach." Several men and women also mentioned that microbicides could be distributed like condoms, through vending machines located in toilets, schools, taxi stands, or transportation hubs. Experience with condom social marketing led a representative from a national NGO to conclude that public clinics, supermarkets, and chemists would not be the best places to reach youth because the 40 percent of young, sexually active people cannot access them at these places. Rather, the "best place would be the mama sitting at the entrance to school with her vetkoek [doughnuts]. That would be the best place." Some community respondents also felt it would be possible to distribute microbicides at schools so that children could take them home to their parents. That said, several community members noted concerns about the quality of products procured from certain commercial locations. The most common of these concerns was the potential of receiving a product that was too old, had been tampered with, or was not of good quality. For example, several community members did not feel spazas were "clean" or that their proprietors likely to maintain an up-to-date stock.

Providers also had concerns about microbicides being provided in dispensers without any formal counseling, especially given partial effectiveness, and suggested that microbicides should be introduced first in the health services, "and then as soon as people accept the product like the condom, then we can start...so it is easily available."

While many policy makers and key policy influentials generally endorsed the idea of distributing microbicides in public facilities and beyond, they also warned of the financial and logistical difficulties of introducing something new in the public sector, and expressed concerns about ensuring a reliable and affordable supply. Several policy makers and community members interviewed stressed the need for a comprehensive introduction strategy that includes government departments both inside and outside the 
health sector. Another key policy influential stressed the need for the public and private sector to work together. In the words of a community health worker, introduction must be approached "from all angles," including labor unions and health and non-health organizations, in order to "counter the fear of the unknown."

\section{b. Assuring sustainability of supply}

The experience of policy makers, key policy influentials, and providers with the introduction of other reproductive health technologies clearly colored their ideas about the pace and form of microbicide introduction. Respondents from both the public health sector and nongovernmental organizations spoke at length about their experience with the female condom, in which expectations for the product were raised within communities and there was not a sustainable supply to meet that demand. Several respondents recognized the difficult balance between the need to market and create demand before introducing microbicides, and the importance of systems to meet the demand that is created.

"We have done very well in terms of creating a demand, but in a lot of instances for a number of years we didn't make the products easily available. Classical example is the female condoms. We created a hype and when people rushed to get the products, what did they see? 'No, they are not available."”

-National policy influential

Partly to help avoid these problems, several provincial and national key policy influentials suggested gradual introduction by marketing microbicides first in pilot sites in both the public and private sectors and via nongovernmental and community based organizations.

One provider attributed shortages to "erratic supplies" and was concerned about promoting microbicides without some guarantee that they would be sustainable in both cost and supply. Based on experiences with condom distribution, one policy maker described the effect of stock shortages on access: "We have to wait for the next lot of shipments to arrive, and then you sit for three months without condoms." Such shortages were considered very problematic, particularly early in an introduction process.

\section{E. FINDINGS RELEVANT TO POLICY DEVELOPMENT AND ADVOCACY}

A range of issues with implications for microbicide policy development and advocacy emerged from this study. One key issue relevant to policy and advocacy was the need for information for policy makers, providers, and potential users. Recognizing that the provision and dissemination of information are crucial components of any introduction strategy, respondents at all three levels of inquiry described the types of information that would be important for making a decision about the introduction or use of microbicides. Respondents also raised concerns and offered opinions about challenges related to the cost of microbicides: the cost to the system of introducing the product and the cost to the consumer. Finally, they offered insights on effective approaches to product positioning and marketing.

\section{Information needs}

Policy makers emphasized that they would want access to results from both animal and human clinical studies to determine whether microbicides were safe and effective and to develop a clinical protocol and recommendations for providers. A national policy influential and several focus group participants requested information on the results of completed clinical trials and ongoing trials being conducted in South Africa. Publication of both types of information in respected journals would be important in 
helping to allay the fears, mistrust, and misinformation associated with the AIDS epidemic generally and, more specifically, new medical technologies such as anti-retroviral drugs or microbicides. He stressed that information about on-going trials might help to ensure that it is "not so much of a surprise when the product is eventually registered and approved for use."

Men and women in community focus group discussions were also interested in knowing, and in some cases seeing, evidence as to whether microbicides were "successful." In a group of taverners, several men were afraid that people would begin using microbicides only to learn that they were ineffective. Several respondents underscored the importance of hearing from trusted and credible people, one respondent suggesting that it would be useful to bring a person who had personally used the microbicide to testify to its effectiveness. Another respondent stressed that, "It's important that a black person explains to another black person as opposed to a white person." One man stated, "Not having enough information on the method could cause fear."

National policy makers suggested that clients would also want to know if microbicides could prevent pregnancy, how long they would be effective once applied, and what to do both before and after intercourse. They also said that, before they recommended widespread use of microbicides, they would want evidence that microbicide use would not lead to a decrease in condom use or undermine the condom program.

Community respondents were quite explicit about the types of information they would like to have about microbicides: women would want to know how to apply it, how long it lasted, whether one needed to reapply after washing, and whether it prevents pregnancy. Lack of information could cause their partners to believe that the gel could give them infections, and men might also be suspicious if they did not know that microbicides would be for their protection as well. Male community members were most interested in how much microbicides would cost, how long in advance a product could be applied, whether one could wash or urinate while using a microbicide, and whether it was "suitable for all female age groups." Men also wanted to know whether microbicides protected against only HIV or also against other STIs and pregnancy, and whether the products would have an expiration date.

Similar to policy makers and community members, providers stressed the need to offer potential users detailed information about how microbicides work and how effective they are so that women and their partners could make informed choices about whether or not to use them. Community health workers concurred, and also wanted to be informed about effectiveness, side effects, costs to the client, and distribution points to effectively advise users. They also requested counseling guidelines so they could understand how this critical information should best be conveyed to clients.

"The client actually understands,... what one is talking about, whether it's pregnancy protection, whether it's HIV, STI protection and if there's any sort of lack of clarity around, then [providers] should rather not offer [microbicides] and just stress that the condom is still the health standard. You know, this is just an extra weapon."

-Public health doctor

\section{a. Sources of information}

Both public and private physicians stressed the need for pamphlets or small booklets to detail how to use microbicides and to describe any side effects. Some also suggested that posters with simple messages were important means of communication. Provincial and national policy makers noted that pamphlets had been used in previous HIV/AIDS education efforts with varying levels of effectiveness. One policy maker stressed that information should be "people-based rather than pamphlets," and a journalist suggested conducting workshops in people's own languages. 
Respondents at all three levels of inquiry, but particularly community participants, stressed that individuals providing information often act as advocates for products and may influence acceptance and use of microbicides at the community level. In addition to providers, potential advocates included family and friends, schools, community leaders, traditional healers, community based organizations, and the church. There was a clear call to involve communities, particularly organizations and leaders, in the introduction and dissemination of microbicides.

For example, a national policy maker pointed out that young girls in South Africa are often well organized and motivated to engage in prevention promotion activities, and youth groups could provide useful support. Other policy makers and community members agreed that parents, particularly mothers, could also play an important role in influencing their children's sexual behavior. Others cautioned that not all parents were aware of their children's sexual activity, and others felt that parents could have a negative impact if they perceived that microbicides would give children license to become sexually active at an early age.

Some policy influentials pointed out that, although some churches oppose condoms, they may not oppose microbicides, since condoms prevent pregnancy and microbicides may not. Churches have been involved with and provided support for people living with HIV/AIDS, and many have very active youth programs; one policy influential noted that almost 80 percent of young people profess an association with some faith-based organization. A nurse also mentioned that youth participate in church-sponsored groups, such as choirs, which would offer a good forum for advocacy activities. A community member interviewed suggested that if you want people to believe in an idea "and take it to church, they are bound to believe in it." Another national policy maker pointed out that faith-based organizations already provide a substantial amount of support for women who are HIV positive and their families, and they could also help advocate for microbicide use. From a more practical standpoint, a community health worker noted that priests often offer marriage counseling, which could be an important venue for discussing microbicide use in addition to other reproductive health issues.

At all three levels of inquiry, respondents felt that the recommendations of health service providers played an important, albeit not solitary, role in shaping men and women's sexual behavior. Several policy makers felt that in addition to training clinic-based providers, it would be important to involve community health workers and traditional healers in promotion and counseling programs. One national policy influential noted that many men and women may visit traditional healers if they have problems associated with microbicide use. The key policy influential suggested involving and training traditional healers to serve as counselors and advocates, similar to health intervention models against tuberculosis in the Eastern Cape.

\section{Cost}

Respondents at all levels were concerned about the cost of microbicides to the consumer. Varying opinions were expressed on the pros and cons of providing microbicides free of charge, and on the price that consumers might be willing to pay. Policy makers and some providers had substantial concerns about the cost to the health system, whether the product was to be provided free of charge or not.

\section{a. Cost to the consumer}

National and provincial policy leaders and providers all stressed that microbicides should be accessible to clients and provided at low or no cost, or at least be provided free in public facilities.

Two providers based at public health facilities stressed that microbicides needed to be affordable in order for them to recommend them or clients to use them on a regular basis. While few providers mentioned a specific price, one private provider suggested it should cost less than 30 Rand (approximately \$4 US), 
roughly the average cost of STI treatment. To make microbicides accessible to youth and adolescents, a national policy informant felt they should be available at an extremely low cost-perhaps 50 cents (in Rand). They looked to government to play a main role in making microbicides accessible, even if they are not free, as "it's the government's responsibility to look after the people especially in health and work related matters." Some respondents, however, questioned whether the government could afford to provide microbicides at low or no cost. Several national and provincial policy makers also stressed that microbicides should be priced competitively with condoms or, in some instances, the female condom. In the case of the latter, national policy makers recognized that the possibility of repeat use of female condoms should also be considered when pricing microbicides.

Contradictory views were raised at the community level about the cost of microbicides, with some pointing to the high rates of unemployment as a limitation on people's capacity to buy the products. Others stressed people's desperation to use some form of protection in light of the high levels of HIV and other STIs. Many focus group participants were concerned that if microbicides had to be bought, this would exclude access and availability to those who did not work.

"If it's going to be sold then that is wrong. Where are we going to get the money? If it costs, let's say R30 or R50, who has that kind of money? Then they better forget all about it and let's stick to the condom"

-Male taverner

Many community members said that, although money was scarce, people were desperate and would find money to buy the product. One young woman said that, to her, "Price wouldn't matter as long as there's a guarantee that one wouldn't get HIV and that it's got no side effects. I would go for it because my life is more important." Others felt that if a microbicide cost too much some people would not be able to afford it. She suggested that it not cost more than 5 Rand "because some don't work and condoms are free at the clinic." A private doctor pointed out that there's a problem if the person can afford to try the product but not to continue to use it. "Cost is a major thing when you're working in the townships."

Discussions at various levels also centered on whether people would consider products distributed at no cost as being inferior. Community members pointed out that free methods such as condoms are of notoriously poor quality, and that the condoms from public health clinics are not used because people perceived them to be "weak," i.e., not very effective. A participant in a focus group of nurses concurred that condoms distributed free in clinics are often popularly perceived to be of inferior quality.

Contrary to the prevalent point of view that microbicides should be low cost or free, some policy makers mirrored the perceptions of clients and supported the assertion of social marketers that products distributed in the public sector or free-of-charge are seen as inferior to other methods or products. Others had very mixed views on whether microbicides should be free or bear some cost.

"People perceive things to be from the government as negative and going back to the apartheid days where people think 'whatever the government's giving me is inferior. And maybe they've got a plan, maybe they just don't want me to have children', all of those ideas... Also, there's this thing of where people pay for things they seem to appreciate it more and place more value on it...But also you want them to be available to people, you don't want the fact that the person is poor, and they can't afford it...for me it's probably going to be best to go with something that is free.."

-National policy influential 


\section{b. Cost to the health system}

Some policy makers expressed concerns about the cost to the health system, the limited resources throughout all levels of the health system, and the difficult decisions that must be made among competing priorities.

"We're sitting on a ridiculous situation that we don't have enough money for vaccines... and cost has become a major factor in terms of what package of health care actually gets delivered... if it comes in at a cost, it needs to be located within the continuum of what the public sector can afford."

-National policy influential

"Effectively, the biggest block to an effective public health service in Cape Town is resources, is funds. And it applies from national, to provincial, to local government already. I mean Health is not getting an adequate slice of the pie...of course as long as we didn't buy submarines and fighter jets and all that we wouldn't have this problem..." -Provincial policy influential

Other policy makers expressed concern about the level of the health system that would bear the cost, and whether officials would be willing to budget for something that may not be highly effective.

"You just need to get the buy-in from...national, provincial, down the line... and funding for it. ... If you didn't-especially if it was costly and if you didn't additionally fund for it-it won't take off, because everybody's pressed in their budgets. So nobody's going to say, 'Well, this might work so I'll take the chance and send another RI-million on this of my district budget.",

-Provincial policy influential

While several national and provincial policy makers noted the financial difficulty of providing microbicides free in the public sector, one provincial policy maker said that if it was felt to be very effective, "Whatever the price is, we'd buy it."

\section{Product positioning and marketing}

Several respondents had very specific ideas about the types of advertising or marketing messages that should accompany microbicide introduction. A policy maker at the national level stressed the need to "reduce the stigma as much as possible" in order to make the process accessible to everyone. In a similar fashion, another national policy maker felt messages should be general and not be directed at "people who might be sleeping around." In order to interest all women in the product the same respondent felt that information about microbicides should be given to women's groups and organizations or advertised in women's magazines.

Another informant suggested messages needed to stress that "it's cool to use this gel" and for young people to make it "hip and happening." A key policy influential added that it should be positioned as "part of a healthy life for trendy people in South Africa." The respondent felt that microbicides should be marketed as "part of the natural process" rather than as a medication. Another national policy maker also felt the underlying message should be positive: "We need to ... be radical enough to say, 'People enjoy sex so let's do it properly.",

A policy influential was very clear that microbicides packaging should not be linked to AIDS.

"Which person wants to use a condom with an AIDS ribbon it? I mean, that's ridiculous. Then you've located it very, very firmly in the realm of a medical tool. I just wish the 
government would change their packaging. But it's the same here, don't position this as 'This is about AIDS.' Position it as 'This is about healthy sexuality.'"

-Policy influential

In focus groups, many women felt advertising should be directed toward women, with the packaging "nice and attractive." One woman referred to the container for another product that looks "like candy" and suggested that this would cause a woman's partners also to be interested. In a similar vein, respondents stressed that the packaging should be similar to other commonly-used female products like tampons or suppositories.

In both men's and women's focus groups, participants spoke at length about both the packaging and the type of applicator. A young man suggested it should be marketed in a container that prevents tampering. Another woman in the same focus group stressed that it should be "exciting and relevant to youth" and the package easily recognizable on the shelf.

Respondent discussions of the beneficial or positive characteristics of microbicides may hold important implications for the marketing or positioning of a future microbicide. However, given that participants were discussing a hypothetical product, these findings should be viewed with caution. Nevertheless, both provincial and national policy makers and providers felt that microbicides would be perceived as beneficial if they were more "self-controlled" and "discreet" than existing products like the condom or female condom. A national policy maker stated unequivocally, "Definitely a contraceptive controlled by women themselves in an environment like here, no doubt there is a market." Women felt that because women could apply microbicides themselves and potentially well in advance of either unanticipated or anticipated sexual activity, female consumers would find them attractive. Similarly, women felt that both men and women would find microbicides attractive because they offered a means of protection. In the words of one woman, "It's better to use the gel: simply insert it and put aside." One community member interviewed suggested it should be marketed as an "easier way to prevent infections."

Speaking more generally, however, a few women cautioned that the introduction of new products was sometimes met with suspicion in the community. New products were generally assumed to be "white man's things" that would cause rather than prevent infections. Information and marketing would need to counter such rumors and myths. 
Paving the Path: Preparing for Microbicide Introduction $•$ 48 - Qualitative Study Report 


\section{DISCUSSION}

As with any qualitative research, the findings of this study are not intended for generalization or to be viewed as representative of the perspectives and perceptions of any particular group or population, including the community of Langa. However, study data do echo and expand upon findings in previous social science research and programmatic experience in areas such as product characteristics, condoms and condom substitution, distribution strategies, and lubrication ("wetness"). Additionally, they have yielded several somewhat unexpected yet significant issues for consideration, such as the widespread understanding of women's vulnerability and their need for products like microbicides, and the broad assumptions about microbicide use for protection in case of unplanned sex or rape. In this discussion section, we highlight a number of themes that have direct implications for policy or further research related to product development and introduction.

\section{Support for microbicides}

Until recently, microbicides were largely unknown as a potential HIV preventive, and questions existed about whether such an approach was scientifically or programmatically feasible. Consistent with the growing recognition of the potential of microbicides, respondents across the range of categories expressed strong support for product development and introduction. This interest derived from several related underlying issues that were described frankly and at times eloquently.

First, participants exhibited widespread understanding and recognition of women's social vulnerability to infection. Many spoke openly and spontaneously about the underlying social, economic, and political factors that contribute to women's lack of control over sexual relations, and their concomitant vulnerability to HIV infection. Given the devastating impact of the HIV/AIDS epidemic in this setting, there was a real sense of desperation among community participants, providers, and policy makers for anything that could help stop the spread of HIV.

Second, while respondents in all groups felt strongly that condoms must be promoted and supported, there was widespread recognition, and at times resignation, about the limitations of condoms that echo the findings of much previous research: people don't use them, especially in primary partnerships; they interfere with intimacy and sexual pleasure; they prevent pregnancy; and so forth. Recognizing the limitations of current prevention strategies, there was a strong sense that additional prevention technologies and approaches are urgently needed, especially those that women can control. A number of policy makers and community members were already aware of microbicides due to ongoing research in South Africa, including a trial conducted in another part of Cape Town. However, few had a clear understanding of product approaches or indications, and a number had misconceptions about microbicides. Given the devastating nature of the HIV/AIDS epidemic, there was an enormous sense of urgency and real frustration at the relatively long timeframe before an effective microbicide could potentially be made available.

Despite some concerns, the need for microbicides and their potential resonated strongly with those interviewed for this study. This may be largely due to the level of the epidemic and vigorous public discourse on the issue. Strategies for developing support for microbicides will clearly need to be tailored to other contexts. Even with the significant support among those interviewed for this study, respondents expressed a number of concerns and uncertainties about microbicides, and an understandable need to know more about a specific product before they would approve, recommend, or use it. Therefore, while there seemed to be general support for a product like a microbicide, it is not clear whether such support for a hypothetical product would necessarily translate into practice. This also suggests that a more specific case will need to be built based on the evidence from research and characteristics of a particular product. 


\section{Implications of a partially effective product}

As expected, the issue of partial effectiveness emerged as a major concern, particularly among providers and policy makers. Microbicides were described to study participants as products under development, with the first generation of products expected to be partially effective, with a range estimated from 40 $70 \%$. Initially, respondents across all three categories expressed some unease about the implications of introducing microbicides as a "stand-alone" product, given that they will be less effective than condoms. When considering how to introduce microbicides into existing prevention programs, many were more comfortable with microbicides as a "complement" or "addition" to existing prevention options. However, in a number of instances, after considering women's vulnerability, their limited choices, the reality that people often can't or don't use condoms, and the urgent need for more prevention strategies, many recognized that even a partially effective method could be an important part of the overall HIV prevention effort.

A few providers, in particular, questioned whether introducing a product less effective than condoms would be ethical, especially if it encouraged people to switch from using condoms, and expressed concern about their own ethical and legal liability if a person using such a product became infected with HIV. In general, providers and policy makers accepted that such products would be introduced in the context of other prevention methods, and might be recommended for use with condoms. While some questioned the practical feasibility of encouraging such dual-method use, there seemed to be a much greater comfort level with including microbicides as part of a hierarchy or method mix so that people would be able to choose from more options. Several providers expressed their own frustration at continually recommending that clients use condoms, knowing that many choose not to or are not able to, and that there is little else to offer them.

Providers' and policy makers' concerns about partial effectiveness evolved from initial apprehension about practical and ethical implications, to a more positive and affirmative view of the role microbicides could play in reducing individual risk and population-based incidence. In many cases, this evolution in thinking occurred during the course of the interview without prompting or intervention on the part of the interviewer. This underscores some of the complexities of resistance to microbicides and suggests that some initial concerns and assumptions may be amenable to change.

The varied ways in which partial effectiveness was understood and discussed in relation to risk across all respondent categories underscored the challenges in accurately conveying complex messages about risk reduction and the options presented by a partially protective product. Other studies that have examined risk behavior, HIV, and condom use suggest that risk perception is highly specific to individual circumstances. This suggests the need for further targeted research on specific understanding and assessment of risk, practical approaches to conveying concepts of partial effectiveness, and implications of both for microbicide introduction.

\section{Condoms and condom substitution}

Policy and provider-level respondents expressed some concern about the possibility that people may switch from condoms to microbicides; thus, introducing microbicides would undermine condom promotion and use. Some community members confirmed this possibility, indicating that they would welcome the availability of microbicides primarily because they would provide an alternative to condoms. Ironically, several women participants and providers also suggested that microbicides could actually decrease women's ability to negotiate condom use and thus increase their risk if partners insisted on microbicides instead of condoms. There was little discussion about people's perceptions or assumptions about the particular circumstances and types of relationships in which condoms or microbicides would be used. Given our growing understanding about how relationships and other circumstances influence condom use, it would be useful to explicitly explore these themes with respect to microbicides. 
Policy makers and providers sought to balance their concerns about condom substitution with acknowledgment of the realities of condom use. They reflexively positioned condoms as the "gold standard," although on further reflection most acknowledged the condom's limitations. They were particularly concerned about the implications of condom substitution for adolescents, who were perceived as at high risk and as having made some progress with using condoms. Findings suggest that while it is critical to continue to promote condoms and develop supportive strategies, it is also important to develop policy approaches and messages around introducing microbicides that accurately reflect actual levels of condom use and the impact that condoms have on risk reduction, rather than a theoretical ideal. In addition, concerns about condom substitution will likely shift with any changes in patterns of condom use that may occur. For example, if condom use increases, condom substitution will likely become more of a concern. Given the long timeframe for microbicide development and introduction, this issue will need to be continually revisited.

\section{Rape and unplanned consensual sex}

One of the primary unexpected findings was the degree to which respondents across levels, but particularly community members, assumed that an important application for microbicides would be use by women to provide protection if they were raped. This issue arose consistently and spontaneously in all respondent groups except providers. Rape is widespread in South Africa and has been extensively discussed and debated in the public arena. Both these factors have contributed to an acute awareness and perception among many South Africans that rape constitutes a very immediate risk in women's daily lives. Women also discussed the utility of microbicides in the case of unplanned consensual sex. Both of these uses imply an assumption that women would be able to apply a microbicide as part of a daily routine.

These findings have several concrete implications for microbicide development and introduction. This kind of application would necessitate that a microbicide has a relatively long duration of action, and that it would be both affordable and convenient enough to be used daily or even more frequently. While it is uncertain whether products could meet these expectations, it is encouraging in that people seemed willing to use microbicides or assumed that they could use microbicides on a routine basis. This also has implications for how microbicides could be introduced or marketed. While it is unlikely that any marketing strategy would focus on the risk of rape or sexual violence, these findings suggest an opportunity for building on the security of feeling protected "just in case."

\section{Wetness, lubrication, and intravaginal practices}

The issue of "wetness" resonated strongly with study respondents as a serious concern and arose spontaneously within discussions on a range of topics. It has been an ongoing concern in the microbicide field that the lubricating properties of current gel formulations could compromise widespread use of microbicides. In this study, wetness had primarily negative associations with infidelity, lack of sexual pleasure for men, or STIs. In some cases it was also recognized as associated with women's sexual response and as something that women would welcome. Respondents across categories had quite different perceptions about how important added lubrication might be in hampering microbicide acceptability and use. The lively discussions and wide-ranging interpretations of lubrication underscore the need to examine the actual meanings associated with wetness and lubrication in different settings rather than relying on assumptions about practices or preferences

Similarly, it is important to examine actual experience with respect to intravaginal product use and other intravaginal practices. Some policy makers thought that women would be uncomfortable with inserting a product vaginally. However, most women were quite familiar with using products intravaginally, especially for common RTIs, and spoke frankly about using vaginal creams and tampons. Beliefs and assertions by policy makers that "women won't use them" because they are inserted vaginally could 
erroneously inhibit support for microbicide introduction even in settings where such products are used regularly.

\section{Product characteristics}

Findings from this study confirm and further define preferences for microbicide product characteristics that have been suggested elsewhere. For example, while most respondents acknowledged that HIV is the most urgent concern, there was a strong preference for a product that is effective against a range of STIs. This was expressed particularly strongly by providers and likely reflects the significant burden that STIs impose on individuals and the health system in this community. While some respondents felt that a product that provides dual protection against pregnancy and HIV would be most convenient and appealing, many felt strongly that a non-contraceptive microbicide was more important. Several eloquently described the terrible dilemma faced by women and couples who want to, or need to, conceive but do not want to risk HIV infection. It is important to recognize that perceptions regarding contraceptive versus non-contraceptive properties are likely to vary where contraceptive prevalence is low, unlike South Africa.

Many respondents assumed that microbicides would remain effective for long periods after insertion. These assumptions emerged most dramatically in the context of rape (described above) but also surfaced in comments about the product being used as part of a daily routine, like a deodorant. Wetness and lubrication were major topics of discussion, among all respondent groups, as described above. People spoke openly and creatively about the importance of developing products with different smells, tastes, and packaging and marketing approaches to appeal to a wide range of users. This further underscores the need to develop a range of products that can meet different health and consumer needs and preferences.

\section{Potential users}

Findings from this study suggest that microbicides could be positioned for a wide range of potential users. While in other settings people often assume that high-risk groups, particularly sex workers, would be the most likely and appropriate users for microbicides, respondents in this study cited a much wider range of potential user groups, and only providers discussed "high-risk groups," including sex workers. First, it was nearly universally assumed that younger, unmarried women, including youth, would be important users of microbicides. However, while this was strongly supported by providers and community members, policy makers were less supportive of youth being targeted due to concerns that it would increase youth's risk and potentially undermine recent gains in condom use. Reflecting widespread concern about child rape, a number of people also suggested that microbicides could offer protection for children who are at risk of sexual violence and rape. Another category identified was "older" married women who are still sexually active with their husbands from time to time. The idea of HIV-positive people using microbicides was raised, although not explored thoroughly. The possibilities for HIVpositive people using such products to prevent secondary transmission, to prevent re-infection, or to prevent other STIs are additional areas for further exploration.

One of the more interesting and encouraging elements throughout these discussions was the sense that microbicides would be "mainstream" products. Even sex workers themselves discussed microbicides in the context of mainstream use rather than in the context of sex work, possibly because sex workers are already using condoms somewhat successfully and the need is greater for single or married women who have difficulty negotiating condom use. There was little stigma that seemed to be associated with microbicides or with the women who might use them. The overall tenor of the discussions and specific suggestions about potential user groups suggested very pragmatic and non-judgmental analysis of the risk of HIV infection and the real obstacles women face in protecting themselves. 


\section{Positioning and distribution strategies}

Suggested distribution strategies underscored the tension between the need to maximize accessibility through making microbicides widely available in a range of clinical and non-clinical outlets, and the need to control distribution and provide counseling. Information and counseling were considered essential in order to convey complex messages about risk reduction and partial effectiveness and to assure fully informed choice. Community members noted that periodic supply shortages and erratic hours of operation in the public sector may make access to microbicides in the public sector difficult. They suggested a wide range of potential distribution points and strategies, including pharmacies, kiosks, and other shops where medicines and other consumer goods are sold. This was reinforced by several community leaders who cautioned against "medicalization" of the product and stressed the need to present products as appealing, fun and "normal." However, policy makers, providers, and community members were all hesitant to endorse widespread distribution without adequate counseling or information. There was some support for a compromise approach in which products could be first introduced through a more formal clinical setting; once the public is familiar with the products' attributes and has some experience using it, more widespread availability could be phased in over time.

In general there was a strong sense that the best approach to positioning and marketing microbicides is to build on strong, affirmative messages that will associate the product with a healthy, dynamic, positive, and modern lifestyle.

\section{Raised expectations and ensuring supply}

A number of respondents in all categories underscored the importance of careful planning to balance creating demand with having the systems and infrastructure in place to meet it. Many people referred to the problems experienced with the female condom in South Africa, where introduction studies and efforts created demand for the product but the procurement and supply systems were initially not in place to adequately meet that demand. This example has important lessons for microbicide introduction.

Damaging long-term effects can result if expectations are raised that cannot be met. This can undermine introduction and confidence in a product and in the health system as a whole.

Because microbicides are a new product category, an accurate prediction of demand for the first microbicides in different settings will likely be very difficult. Given how urgently these products are needed, there will likely be pressure to produce and introduce them rapidly.

Community members, and particularly providers and policy makers, had a strong "institutional memory" about lessons learned in different types of product introduction. This could potentially serve as a useful resource for considering how best to manage introduction of microbicides and other products. However, examples like the female condom may also make people cautious about embracing a new technology, particularly one that is so eagerly anticipated and urgently needed. 
Paving the Path: Preparing for Microbicide Introduction -54 - Qualitative Study Report 


\section{RECOMMENDATIONS}

The recommendations presented below have been selected to draw attention to some of the less expected findings and to areas requiring careful analysis in other geographical, social, and epidemiological contexts. This study was conducted in only one community in South Africa for the community and service delivery levels of inquiry, and with provincial and national respondents for the policy level. The results are therefore not necessarily representative of South Africa or beyond, but instead are meant to assist in framing the issues for microbicide introduction strategies and identifying questions and issues for further research.

\section{“MAKING THE CASE” FOR MICROBICIDES}

- "Make the case" for microbicides based on specific setting: Further research in other geographical and epidemiological settings is needed to determine the best approach to "making the case" for microbicides. In this study, there appeared to be little need to convince people of the need for a product like microbicides. However, in the South African setting, the epidemic is at a very high level, and there has been a great deal of vibrant and open public discourse about HIV/AIDS, as well as some exposure to the concept of microbicides due to preparation for clinical trials. The broad recognition of the need for microbicides found in this study may not carry over to other settings where such issues are more hushed and stigmatized, where women's vulnerability is not as well recognized, where public discourse about AIDS and microbicides is low or absent, and where cultural differences place greater restrictions on open discussion of sexual behaviors and practices.

- Communicate the rationale: Efforts to evaluate the acceptability of microbicides on the provider and policy levels will require dialogue and probing beyond immediate responses. Likewise, efforts to communicate the rationale behind microbicides will require more than simple messages. Despite the broad support for microbicides among respondents in this study, initial responses were more mixed and muted. During the course of the discussions, some respondents who initially expressed concerns shifted to a positive sense of the need for microbicides. Opinions changed when people talked through the issues to arrive at their own conclusions, a finding that points to the value of qualitative research for a more in-depth exploration of issues. This suggests that initial perceptions and positions about the product may not be immutable, and that relying on initial responses may not yield a full consideration of the issue and a true response. These findings also suggest the need for advocacy and introduction strategies to assure adequate dialogue with individuals who are likely to support or inhibit introduction.

- Understand how the "prevention equation" can be used: Further investigation will be needed to determine how the prevention equation is understood, and whether and how it could help make the case for microbicides. In this study, the prevention equation did not appear to be particularly important in convincing policy makers of the value of microbicides. It was explained to all providers and policy makers as part of the introduction to the interview, but received little reaction, possibly because it was not well explained, possibly because the importance of microbicides was already well-understood, or possibly because it simply was not an effective argument. However, this may differ in settings where the AIDS epidemic has not had as substantial an impact, and microbicides may not be as readily accepted or supported. 
- Use information on intravaginal practices to counter erroneous assumptions: Introduction and advocacy efforts should take into account the fact that assertions or assumptions that women will not use intravaginal products may not hold true. In this study, notions expressed by policy makers about women being unfamiliar with or unwilling to use intravaginal products were not confirmed by providers and community members. In fact, many responded that women were quite accustomed to using vaginal products. Introduction and advocacy efforts may benefit from the use of local data about actual use of intravaginal products to counter erroneous assertions that could undermine introduction efforts.

\section{Developing Introduction Strategies}

- Balance broad access with the need for counseling and informed choice: The possibility of using distribution channels outside of the health sector, or outside of clinical service delivery, should be further explored in preparing for introduction. It will be important to determine how to balance interest in broad access with the need for careful counseling. Community respondents indicated interest in a wide range of distribution points, and also pointed to obstacles to accessing products in the public sector, including erratic hours of operation, constant shortages of supplies, and poor treatment by providers.

- Address provider information and training needs: In order to assure support from health providers and their participation in introducing microbicides, introduction strategies must pay careful attention to providers' information and training needs. Providers could be pivotal in influencing microbicide use. Providers indicated a need for in-depth information in order to feel comfortable recommending microbicides, including knowledge of side effects and results of clinical studies demonstrating effectiveness and safety. Providers want to be consulted and involved up-front, given that they are in the "front line" in distribution, counseling, and promotion. The issues surrounding microbicides are complicated, and providers will need training to develop the skills and comfort to effectively introduce the products, including the ability to articulate the advantages and disadvantages of microbicide use, to explain partial effectiveness, and to help clients communicate with partners. Although most providers in this study would likely support microbicides given adequate information, providers in other contexts may not be as receptive to such a product.

- Market for use with or without a partner's knowledge: Marketing and introduction strategies should take into account the need for both covert and overt use of microbicides. This study clearly demonstrated the desire by both women and men to communicate about microbicide use; however respondents also recognized the many circumstances that would require use without a partner's knowledge, and they noted the benefits of having a method that could not be detected. Depending on actual product characteristics, covert use may be more or less feasible; marketing strategies could also influence the feasibility of covert use.

- Consider youth as a potential target group for microbicides: Youth need to be seriously considered in clinical studies, introduction strategies, and further research as a potential user group for microbicides. Young people were spontaneously, readily, and consistently identified in this study as among the primary potential users of microbicides, despite some strong reservations about possibly undermining recent gains in condom use. The results point to the need to develop strategies that actively facilitate access and use by youth in South Africa. In different settings, even with similar needs, young people's access to sexual and reproductive health services may be more constrained and receptivity to them as a user group may be different. 
- Ensure a balance of supply and demand: It will be critical to assure that reliable supply and delivery systems are in place before demand is created; demand creation should be carefully balanced with supply limitations to avoid potential backlash against the product. This is particularly important during the critical and sensitive introduction and scale-up stages. Although in this study only a few respondents expressed concern about broad distrust of "the system," where this is more widespread due to historical abuses or perceived manipulations, introducing a product and failing to meet supply needs could potentially exacerbate such distrust, which could slow or halt introduction efforts.

- Enlist multisectoral support for introduction: Involving a broad range of sectors in the public domain as well as elements of civil society will be critical to assuring smooth introduction and should be taken into account in introduction strategies. Given the complicated nature of microbicides and concerns around partial effectiveness, enlisting the support of broad segments of society may be critical. Several policy makers, policy influentials, and community key informants in this study stressed the importance of enlisting the support of individuals and organizations inside and outside of the health sector. The support of community groups, churches, labor unions, and others may be essential to counter potential fear of the "unknown" that may come with the introduction of a new product.

- Address diverse needs: It will be important to determine the possibilities for different microbicide products to meet diverse needs and to continually reassess these as new products with different characteristics become available. This research suggests interest in both free and low-cost products, the potential for use with or without a partner's knowledge, and appeal to different user groups, including married or unmarried people, youth, and sex workers. It also suggests the need for use under varying circumstances, such as daily routine use in case of the unanticipated sex, and use in specific situations or with specific partners. Product characteristics such as contraceptive properties, effectiveness for use by HIV-positive people, and different formulations (gel, suppository, film, etc.) could affect the range of potential market segments and needs.

\section{Further Research}

- Use qualitative research to understand the complexities of perceptions about microbicides, and to allow new ideas to emerge: Further targeted, qualitative research designed to allow emergence of new ideas would be valuable to inform introduction strategies and to better understand the potential facilitating factors and barriers to microbicide introduction and use. In this research, effort was made to identify critical issues up-front based on previous research, review of the literature, and discourse in the microbicide field. Nevertheless, several important issues that had not been anticipated emerged from the research. For example, the prevalent notion of routine microbicide use as a response to the threat of rape or sexual coercion, the notion that microbicides would be useful to put in "before you go out" in case of unplanned sex, and the importance of youth as a primary user group all emerged quite strongly from the data.

- Understand the meanings and implications of "wetness": Further research is needed in South Africa and elsewhere to understand the implications for microbicide introduction of the notion of "wetness." This study confirmed that "wetness" is a major concern in this setting, although the manner in which respondents understood wetness was quite nuanced and multifaceted (e.g., implications of infidelity, reduced sexual pleasure, STIs), and did not necessarily reflect "dry sex" that has been a concern in HIV-prevention efforts and discourse about microbicides. This study also confirmed that concerns related to lubrication and wetness are likely to be serious 
considerations in community-level acceptability and use. Still, little is known about how or whether these same concerns would apply in other cultural and geographic settings, and their implications for product development, marketing strategies, and education and counseling approaches.

- Investigate potential stigma associated with microbicides: It will be important to further investigate the implications of stigma for microbicide introduction strategies in diverse settings, particularly in considering distribution channels and marketing efforts. Although stigma against the product itself or against those who might need microbicides did not emerge in this research as a major issue, this may be quite different in other settings, particularly where discourse about HIV/AIDS is less open, or where the epidemic may be at a low enough level that it is not perceived as "affecting everyone." In addition, it will be important to further investigate any associations that may be made between Nonoxynol-9 and microbicides. While the issue did not receive significant attention in this research (in part due to the fact that spermicides are not generally used in South Africa), in other settings there may be still be some stigma associated with the entire class of products based on the results of the N-9 trials.

- Develop approaches to explaining partial effectiveness: Further research will be needed to determine approaches to explaining the meanings and implications of partial effectiveness. Partial effectiveness was clearly a major concern among all groups interviewed. Study respondents varied widely in their understanding of the concept and in their understanding of concepts related to harm reduction. Determining approaches to explaining partial effectiveness for different audiences will be useful to ongoing research, advocacy, and ultimately introduction efforts.

- Investigate the effectiveness and implications of microbicide use by HIV+ women: Given the growing population of HIV+ people in South Africa and elsewhere, further consideration needs to be given to the reproductive and other health needs of this group. This is particularly important in the context of more widespread availability of anti-retroviral treatment in South Africa and elsewhere and in the light of possible interactions between other contraceptive methods, such as hormonal contraceptives for women. 


\section{CONCLUSION}

The challenges facing microbicide introduction are complex, as the findings of this study demonstrate. Respondent views have clearly been influenced by the sense of urgency and desperation in face of the devastating impact of the HIV/AIDS epidemic in South Africa. This study has contributed to better understanding of barriers and facilitating factors likely to influence microbicide introduction in the South African context. For some issues, this has provided a more complete and nuanced understanding of how microbicides are perceived, and the nature of concerns around them. Others have newly emerged from this research.

Some of the findings of this study were not surprising, as they reflect experience with other technologies and innovations, or common assertions that have been made in the discourse on microbicides and HIV. In these instances, study findings provide documentation and confirm these assertions. For example, this research confirmed the widespread concern about partial effectiveness, and the need to develop strategies for presenting and explaining this to diverse interest groups. It also confirmed the notion that assumptions about women's experience with and attitudes about intravaginal product use do not necessarily reflect actual use and comfort with such products. In addition, the findings from this research project also highlighted the fact that recognition of the need for microbicides is strongly influenced by the context, particularly experience with the HIV/AIDS epidemic.

Several findings from this study raised new issues and perspectives that have not been carefully examined, widely recognized, or discussed in the microbicides field. The most dramatic of these is the assumption that microbicides could be used on a routine basis to protect against infection in the case of rape or unplanned consensual sex. Other examples of new perspectives include the strong focus and complex issues associated with youth as among the primary users of microbicides; the assumption that microbicides would be a product for mainstream use by a range of different segments of the population; and the strong provider preference for a product that protects against a range of STIs, with less interest in pregnancy prevention.

Some of the findings appear to be specific to the local context and may not necessarily reflect views in other epidemiological or sociocultural settings. For example, the apparent preference for noncontraceptive properties among potential users and the lack of interest among providers in contraceptive properties may differ in settings where contraceptive prevalence and access to family planning services is lower. The strong desire for data and other evidence to prove safety and effectiveness may stem, in part, from the specific historical context. The fact that the prevention equation had little resonance, the broad recognition of the need for microbicides, and realistic assessment of the limitations of condoms may also differ significantly.

Many of the issues examined in this research will require further investigation and consideration in other epidemiological and sociocultural settings. Some will prove to be broadly applicable, while others will be more specific to the local or national context. Successful and rapid introduction of microbicides, critical to providing women with a prevention approach they can control and to stemming the HIV/AIDS epidemic, will clearly require further research, advocacy, and careful preparation.

Finally, an important limitation of this research is that the product that was described and shown to respondents is still hypothetical in terms of its physical properties, degree of effectiveness, side effects, and so forth. Therefore it is important to caution that perceptions and opinions-positive or negativeabout these potential products should not be over interpreted. It is unclear whether the relatively enthusiastic responses to this hypothetical product would be borne out when confronted with a decision 
about whether to approve, promote, or use an actual microbicide product. This is likely to be influenced by a complex calculus among the actual product's characteristics, the nature of the sexual relationship, the other available prevention options, and the complex social and epidemiological context of the AIDS epidemic. 


\title{
VII. APPENDIXES
}

\section{APPENDIX 1: Research sampling by respondent categories}

\author{
FGD sessions \\ IDI Respondents \\ (total participants)
}

\section{Community Level}

Women 18-25 - Lower SES (Joe Slovo informal

2 (20 participants)

settlement)

Women 26-45 - Lower SES (Joe Slovo informal 2 (20 participants)

settlement)

\begin{tabular}{ll}
\hline Women 18-25 - Medium SES (Rented) & $2(19$ participants $)$ \\
\hline Women 26-45 - Medium SES (Rented) & $3(30$ participants $)$ \\
\hline Women 26-45 - Higher SES (Homeowners) & $2(20$ participants $)$ \\
\hline $\begin{array}{l}\text { Men 18-25 - Lower SES } \\
\text { (Joe Slovo informal settlement) }\end{array}$ & 1 (7 participants) \\
\hline $\begin{array}{l}\text { Men 26-45 - Lower SES } \\
\text { (Joe Slovo informal settlement) }\end{array}$ & 1 (10 participants $)$ \\
\hline Men 18-25 - Medium SES (Rented) & $1(10$ participants $)$ \\
\hline Men 26-45 - Medium SES (Rented) & $1(10$ participants $)$ \\
\hline Men 26-45 - Higher SES (Homeowners) & $2(18$ participants $)$ \\
\hline Female Taverners & $1(10$ participants $)$ \\
\hline Female Sex Workers & $1(10$ participants $)$ \\
\hline Male Taverners & $2(20$ participants $)$ \\
\hline Women \& Men (teachers) & $1(9$ participants $)$ \\
\hline Community Key Informants
\end{tabular}

\section{Service Delivery Level}

Public Health Practitioners

Private Practitioners

Public Health Managers

Nurses 1 (5 participants)

\section{Policy Level}

\begin{tabular}{|c|c|c|}
\hline National Policy Influentials & & 3 \\
\hline Provincial Key Policy Influentials & & 6 \\
\hline Media & & 1 \\
\hline Professional Bodies & & 1 \\
\hline TOTAL & 23 (218 participants) & 38 \\
\hline
\end{tabular}




\section{APPENDIX 2: Socio-demographic characteristics of community focus group participants}

\begin{tabular}{|c|c|c|}
\hline Characteristic & $\begin{array}{r}\text { Men }(\mathbf{n}=75) \\
n(\%)\end{array}$ & $\begin{array}{r}\text { Women }(\mathrm{n}=129) \\
\mathrm{n}(\%)\end{array}$ \\
\hline Mean age (standard deviation) & $31.2( \pm 7.8)$ & $30.5(8.6)$ \\
\hline Age range (years) & $18-45$ & $18-58$ \\
\hline \multicolumn{3}{|l|}{ Age Group } \\
\hline$<20$ years & $5(6.7)$ & $7(5.4)$ \\
\hline $20-29$ years & $32(42.7)$ & $65(50.4)$ \\
\hline 30-39 years & $21(28.0)$ & $37(28.7)$ \\
\hline 40-49 years & $17(22.6)$ & $17(13.2)$ \\
\hline $50-59$ years & $0(0.0)$ & $3(2.3)$ \\
\hline \multicolumn{3}{|l|}{ Education* } \\
\hline Primary & $17(23.0)$ & $19(14.8)$ \\
\hline Secondary & $21(28.4)$ & $55(43.0)$ \\
\hline Matriculation & $32(43.2)$ & $34(26.6)$ \\
\hline Post-matriculation & $4(5.4)$ & $20(15.6)$ \\
\hline \multicolumn{3}{|l|}{ Employment status* } \\
\hline Employed & $4(5.3)$ & $7(5.5)$ \\
\hline Unemployed & $71(94.7)$ & $121(94.5)$ \\
\hline \multicolumn{3}{|l|}{ Type of housing* } \\
\hline Rent home & $39(52.0)$ & $52(41.3)$ \\
\hline Own home & $13(17.3)$ & $27(21.4)$ \\
\hline Informal settlement & $23(30.7)$ & $47(37.3)$ \\
\hline \multicolumn{3}{|l|}{ Marital status* } \\
\hline Married & $17(34.0)$ & $19(20.2)$ \\
\hline Not married & $33(66.0)$ & $75(79.8)$ \\
\hline \multicolumn{3}{|l|}{ Partner status* } \\
\hline No partner & $12(42.9)$ & $13(23.2)$ \\
\hline Lives with partner & $15(53.6)$ & $21(37.5)$ \\
\hline Boyfriend/girlfriend, not cohabiting & $1(3.5)$ & $22(39.3)$ \\
\hline
\end{tabular}

* Indicates missing data. 


\section{APPENDIX 3: Key issues explored by respondent level}

\section{Illustrative Key Issues Across All Levels (Community, Service, and Policy)}

- General perspectives on the concept of microbicides-reasons for support, potential barriers to introduction and use

- Perceived need for, and ability to use, a woman-controlled method for HIV/STI prevention

- Concepts of harm reduction and partial effectiveness; how concepts are understood, perceived, accepted, and best explained; also dual method use (condom and microbicides) and dual protection?

- Perceptions of product benefits and attributes for positioning/marketing

- Potential avenues/venues for introduction, education and distribution-e.g. public and private health services, pharmacies, community outlets (shops and community based health workers/distributors)

- Key areas of information/understanding that would influence recommendations for microbicide use or advocacy for products, or product use

- Norms, values, and behaviors associated with sexuality and accessing technologies to prevent HIV/STIs

\section{Issues for Policy Level of Inquiry}

- Attitudes to introducing/importing a method that is only partially effective

- Understanding of the "prevention equation" - the potential population-level impact and public health benefit of a lower efficacy method if it is more acceptable and therefore used more consistently

- Potential concerns about "condom migration" (i.e. microbicide use replacing condom use)

- Clinical testing/results-Conditions/knowledge necessary for promoting product (e.g. local safety or effectiveness testing)

- Constituencies that could facilitate introduction

\section{Issues for Health Service Delivery Level of Inquiry}

- Experiences with the introduction of other new technologies

- Perceptions of who should and who would use

- The hierarchy of methods: willingness to offer a less efficacious method when clients perceive more efficacious methods as feasible

- Ways of communicating hierarchy of methods to clients

- Information needed by clients prior to being provided with product

- Informed choice for HIV prevention methods: provider inclination/bias re recommendations

- Perceptions of user-controlled and/or less efficacious methods

- Awareness and perceptions of clients' intravaginal and sexual practices

- Perceptions of clients' willingness to use microbicides

- Understanding of gender/power dynamics limiting condom use

- Understanding implications of gender/power dynamics for microbicide use

- Optimal channels for information, counseling and product distribution

- Concerns about microbicide use replacing condom use ("condom migration")

- Providers' attitudes toward discussing sexuality openly and in-depth with clients 


\section{Issues for Community Level of Inquiry}

- Implications of local sexual and intravaginal practices for potential microbicide use

- Perceptions of who might use such a product

- Preferences for male involvement versus covert use

- Perception of partner attitude towards use

- Perceptions of potential impact on sexual pleasure

- Practices related to spermicide use/perceptions of spermicides

- Product characteristic preferences (e.g. lubrication, spermicidal vs. non-spermicidal)

- Potential local advocates

- Willingness to use, based on various levels of efficacy

- Perception of health services and non-health sectors for potential information, counseling and product distribution

- Potential for association of the product only with illicit sex; stigma (e.g. condoms and commercial sex workers)

- Information needed to make informed choice

- Community involvement for introduction/distribution

- Influentials/opinion leaders who influence norms, values, and behaviors related to sexuality and health 


\section{REFERENCES}

1. Allen, D., Simelela, N., \& Makubalo, L. (2000). Epidemiology of HIV/AIDS in South Africa. South African Journal of HIV Medicine (July): 9-11.

2. Beksinska, M. E., Rees, H. V., Kleinschmidt, I. \& McIntyre, J. (1999). The practice and prevalence of dry sex among men and women in South Africa: A risk factor for sexually transmitted infections? Sexually Transmitted Infections, 75(3), 178-80.

3. Civic, D. \& Wilson, D. (1996). Dry sex in Zimbabwe and implications for condom use. Social Science and Medicine, 42(1), 91-98.

4. Coetzee, D. \& Ballard, R. (1996). Controlling the epidemic of sexually transmitted diseases in South Africa: The role of syndromic management. CME 14(6): 819-826.

5. Cooper, D. \& Marks, A. (1999). Research report no. 2. An evaluation of the community-based distribution (CBD) of contraceptives programme in Khayelitsha, Cape Town: Follow-up survey. University of Cape Town: 1-13.

6. Cooper, D. \& Marks, A. (2001). Mid-term review of the reproductive and social development interventions in selected projects in the Working for Water Programme Integrated Rural Development Projects. Research commissioned for UNFPA, the National Population Unit, Department of Social Development, SA Government, Working for Water Programme, Department of Water and Forestry, SA Government, Planned Parenthood Association of South Africa (PPASA). University of Cape Town, April 2001.

7. Department of Health. (2000). HIV/AIDS/STD strategic plan for South Africa, 2000-2005. Pretoria.

8. Department of Health. (2002). National framework and guidelines for contraceptive services.

9. Heise, L. (1999). Topical microbicides. Takoma Park, MD: Center for Health \& Gender Equity.

10. Medical Research Council, Department of Health of SA and Macro International SA Demographic and Health Survey 1998 Department of Health, Pretoria 2001.

11. Sandala, L., Lurie, P., Sunkutu, M., R., Chani, E. M., Hudes, E. S. \& Hearst, N. (1995). "Dry sex" and HIV infection among women attending a sexually transmitted diseases clinic in Lusaka, Zambia. AIDS, 9, S61-8.

12. Strauss, A., \& Corbin, J. (1991). Basics of qualitative research. Newbury Park, CA: Sage Publications 
Paving the Path: Preparing for Microbicide Introduction • 66 • Qualitative Study Report 